\title{
¿Por qué "Neurociencias" y no "Psicociencias"? Godzilla y Bambi en el reino de la epistemología ${ }^{1}$
}

RESUMEN: El trabajo comienza delimitando los conceptos de paradigma, programa de investigación y programa de trabajo de la ciencia y la tecnología con el fin de enunciar una concepción "postkuhniana" de la ciencia y al tecnología. Una concepción que, a entender del autor, se ha aplicado muy poco en la metateoría de la psico(pato)logía, la psiquiatría y las disciplinas de la salud mental.

Se enfoca este ámbito como un ámbito tecnocientífico marcado por dos problemas fundamentales, desde su misma inauguración, constitutivamente interdisciplinaria: el reduccionismo biologista y la influencia directa de todo tipo de deformaciones ideológicas. Las hipótesis general del trabajo es que, en el fondo de cualquier problema teórico y metateórico de la psiquiatría y las disciplinas de la salud mental actuales, estarán siempre influyendo ese dos tipos de problemas. Máxime en el campo de la psiquiatría, que es definida en el trabajo como una disciplina fundamentalmente tecnológica, es decir, técnica con procedimientos y modelos científicos. Se ilustran esas hipótesis con varias situaciones teóricas, técnicas y pragmáticas de nuestra especialidad.

Para terminar, se rastrean las "epistemologías derivadas" presentes en las modernas teorías psico(pato)lógicas y psiquiátricas y se pasa a redefinir las "15 tesis" sobre el tema enunciadas en mi trabajo de 1978.

PALABRAS CLAVE: Epistemología, Tecnología, Ciencia, Filosofía de la Ciencia, Teoría de la Ciencia, Paradigma, Programa de Investigación, Teorías
SUMMARY: The autor sets out to define the concepts of paradigm, research program and scientific and technological working programs in an attempt to formulate a "post-Kuhnian" concept of science and technology. In his opinion, this concept has not merited sufficient attention in the metatheory of psycho(patho)logy, psychiatry and the mental health disciplines.

The analysis focuses on the sphere of the technosciences; a sphere which has been marked from its interdisciplinary beginnings by two fundamental problems: biological reductionism and the direct influence of all types of ideological deformations. The author concludes that the theoretical and metatheoretical problems arising in psychiatry and the mental health disciplines today are influenced by these two problems; particularly so in the field of psychiatry, wich is defined as a fundamentally technological or technical discipline with scientific models and procedures. The author supports his hypotheses with several examples of theoretical, technical and pragmatic situations ocurring in the field. Finally, he investigates the "derived epistemologies" present in modern psycho(patho)logical and psychiatric theories and goes on to redefine the " 15 theses" formulated in his work of 1978. KEY WORDS: Epistemology, Science, Scientific Philosophy, Scientific Theory, Paradigm, Research Program, Theories. 
1. Introducción: sobre el concepto kuhniano de paradigma.

Es evidente que el concepto kuhniano de paradigma, concebido y presentando inicialmente en las sociedades filosóficas, ha hecho (tanta) fortuna que se ha difundido entre las comunidades científicas e incluso en la sociedad en general. El mismo título de este Congreso es una muestra evidente de ello. Probablemente muy pocos conceptos de epistemología o filosofía de la ciencia podrán presumir de haber alcanzado en tan pocos años una tan amplia difusión, difusión en la cual ha jugado un no desdeñable papel el uso previo del término en el idioma castellano -por cierto que con un sentido emparentado con el que más tarde iba a utilizar el historiador y filósofo de la ciencia Thomas S. Kuhn. Desde hace varias décadas, prácticamente desde la traducción al castellano de La estructura de las revoluciones científicas ${ }^{2}$ (51-54, 63-68), el concepto me impactó lo suficiente para que lo haya ido utilizando en todos mis ensayos sobre epistemología de las disciplinas psicológicas y psiquiátricas (94-120). Como otros muchos autores, por supuesto.

Esa generalización de su uso le ha llevado a jugar un importante papel en las polémicas epistemológicas de la segunda parte del siglo XX, tanto en el ámbito de la epistemología de la ciencia en general (lo que Piaget --71-75-- llamó la epistemología derivada) como en las epistemologías internas de las diferentes ciencias. Sin embargo, esa extensión y utilidad de su uso no corre pareja con la delimitación del concepto o categoría de paradigma que utilizó el propio Kuhn o sus seguidores y glosadores. Si uno revisa el libro original de La estructura de las revoluciones científicas (en adelante $E R C$ ) es difícil que halle en él una definición clara y sintética del término. Kuhn se aproxima a esa definición sintética, cuando, respondiendo a los críticos, en la amplia addenda de 1975 (51-54), propone el concepto de matriz disciplinar. Definirá la matriz disciplinar, un término que ya en esa época prefiere al de paradigma -pero que, evidentemente, no ha hecho fortunacon las siguientes características:

1. Un conjunto de generalizaciones simbólicas, una especie de "esquemas de leyes" que en cada ciencia se aplican a diferentes situaciones.

2. Un conjunto de creencias metafísicas que comparten ese grupo de científicos: la creencia en los átomos, en los campos de fuerza, en una visión hidráulica del cerebro, en los neurotransmisores...

3. Un conjunto de sistemas de evaluación de las teorías: ¿cómo pueden evaluarse teorías, leyes, hipótesis para asegurar la consistencia interna, predicciones precisas, problemas fecundos?

4. Un conjunto de "soluciones de rompecabezas concretos... empleadas como modelos o ejemplos" paradigmáticos" (Kuhn 1975: 51-54). Es la segunda acepción del término paradigma: el que lo asimila a "casos o situaciones ejemplares", paradigmáticos, que diríamos en castellano. Es la posesión común de diferentes modelos y ejemplos paradigmáticos lo que define un grupo científico.

Tal conjunto de características constituye el núcleo de la ciencia normal, el período más general y dilatado del desarrollo de la ciencia, en el cual los 
científicos que creen o (o mantienen una com-unión) en determinados paradigmas, se dedican al desarrollo de la ciencia normal y, por lo tanto, a la acumulación de conocimientos: dedican sus energías a resolver los problemas, rompecabezas y enigmas que el paradigma plantea, a realizar aplicaciones, a difundir los puntos de vista "oficiales" de su paradigma, a discutir las anomalías, a enfrentarse con las nuevas teorías y modelos surgidos alrededor de dichas anomalías, a intenta arquitrabar un conjunto teórico, técnico y epistemológico sólido de su ciencia... De vez en cuando, en la historia de todas las ciencias, la acumulación de anomalías hace insostenible e indefendible el paradigma usual y adviene una revolución científica, (lo que en psicología del desarrollo y psicoanálisis llamaríamos una crisis y una transición psicosocial, con su consecuente cambio de perspectiva): las nuevas ideas y el nuevo paradigma, inconmensurable o incompatible con el dominante hasta entonces, derrota o convence a una parte relevante de los científicos $\mathrm{y}$, tras un período de crisis, el nuevo paradigma reina en la comunidad científica -habitualmente renovada al mismo tiempo que se ha renovado el paradigma. Pero la formación o el triunfo de un nuevo paradigma pueden llevar mucho tiempo (a veces siglos, como por ejemplo, en el caso del paradigma geocéntrico de la astronomía precopernicana). Además, durante ese período pueden coexistir dos o más paradigmas, con sus respectivas comunidades científicas -tal como en nuestras disciplinas lleva casi un siglo existiendo el paradigma organicista, el paradigma mentalista, el paradigma conductista, etc.
La polémica ha seguido durante decenios y una muestra de ella son las compilaciones de Imre Lakatos $(53,54)$, con trabajos cruciales como los del propio Lakatos, de Muguerza, de Kuhn, de Popper, de Feyerabend sobre La crítica y el desarrollo del conocimiento (28-32); o como los de Alan Musgrave, discípulo de Lakatos, Los segundos pensamientos de Kuhn (67).

La indefinición y cierta confusión que ha rodeado tanto al concepto como a su difusión llevaron a Imre Lakatos y a sus discípulos a postular su substitución por el concepto de programas de investigación $(53,54)$. Pero tampoco ésta categoría aparece demasiado definida con suficiente precisión en los trabajos de Lakatos que consulté entonces y he vuelto a consultar más tarde (51,53,54, 63-65). Hasta el extremo de que el propio Kuhn ha llegado a decir que su concepto de paradigma coincide con el del "núcleo de un programa de investigación" de Lakatos. Es decir, que el término de programa de investigación, amén de no ser mucho más exacto y estéticamente o lingüísticamente atractivo, presenta asimismo anomalías e indefiniciones. Incluso puede prestarse a nuevas confusiones. Por ejemplo, con respecto a la pragmática de la ciencia. En efecto, desde nuestro punto de vista como practicantes de las tecnologías psicológicas (101-120), el término puede hacer pensar erróneamente que gran parte de la ciencia tiene que ver con los programas de investigación y que los aspectos técnicos, tecnológicos, institucionales, políticos y demás juegan un papel menor de lo que juegan en realidad, problema que, a mi entender, la 
acepción actual del término paradigma, evita mejor.

En realidad, los paradigmas o programas de investigación podrían entenderse como programas de trabajo de la ciencia. El término paradigma resulta difícilmente sustituible, por tanto. Se hable pues de paradigma, de programa de investigación, de programas de trabajo o de matriz disciplinar, la perspectiva de la investigación, al menos en los países dominantes del imperio, hace pensar que dichos programas están formados por:

1. Una serie de creencias metafísicas: la creencia en los átomos, en los campos de fuerza, en una visión hidráulica del cerebro, en la fundamentación de la mente en el cerebro...

2. Un conjunto de modelos, teorías y leyes paradigmáticas, centrales en el grupo o comunidad científica de la ciencia concreta: por ejemplo, los modelos biológicos-genéticos, los de la sociobiología, los de la sociogénesis...

3. Un conjunto de sistemas de evaluación de las teorías: ¿cómo pueden evaluarse teorías, leyes, hipótesis para asegurar la consistencia interna, predicciones precisas, problemas fecundos?. Ejemplos propios de nuestro campo serían las diversas teorías de las técnicas psicométricas, o las diversas perspectivas de la validez de la estadística y /o la epidemiología clínica, de la así llamada medicina (o psiquiatría) basada en pruebas...

4. Un conjunto de "soluciones de rompecabezas concretos... empleadas como modelos o ejemplos" paradigmáticos (Kuhn 1975): es la segunda acepción del termino paradigma. Así por ejemplo, la parálisis general progresiva, o las lesiones cerebrales de la demencia de Alzheimer pueden entenderse como paradigmas de la etiología orgánica de las "enfermedades mentales" (sic.).

5. Una cierta "afición" o "tendencia" hacia determinadas epistemologías derivadas: empirismo, positivismo lógico, racionalismo, realismo crítico, constructivismo, constructivismo dialéctico....

6. Una tendencia a utilizar y desarrollar ciertas aplicaciones técnicas e incluso pragmáticas en vez de otras: por ejemplo, drogas en vez de psicoterapias.

7. Cuestiones de poder y reparto político: en nuestro siglo, una cierta organización de cada comunidad científica como comunidad profesional y corporativa en la cual el reparto de roles entre el Imperio y los centros secundarios juega un papel fundamental, así como entre el poder y prebendas de los defensores del paradigma tradicional, cuando aún no ha entrado en un período degenerativo, y el paradigma alternativo. También unas ciertas normas, a menudo implícitas tan sólo, para el reparto del poder entre las comunidades científicas que trabajan en la ciencia normal, más institucional, y las que trabajan en el momento de la ciencia extraordinaria y las revoluciones científicas, así como entre las que trabajan con paradigmas dominantes y secundarios o progresivos y regresivos...

8. Un conjunto de normas éticas, mitos y actitudes sobre la realidad pragmática y el valor social de la ciencia, muchos 
de ellos difícilmente justificables desde el punto de vista racional: la importancia del efecto Utah, hasta dónde es soportable el efecto Darsee (Clavero 1991 (16), Tizón 2001 (114-115, 119-123)), hasta qué punto los científicos deben plegarse al poder y al capital, etc..

\section{Consecuencias de la epistemología} kuhniana.

El modelo popperiano de la racionalidad científica, y su generalización como racionalismo crítico ha tenido que aceptar, enriqueciéndose con ello, el cambio de perspectiva que la aportación kuhniana suponía de la epistemología, sobre todo desde el punto de vista de la historia y psicología de la ciencia. Como dice Quintanilla (79), la obra de Kuhn podría haberse leído no como una alternativa a la metodología falsacionista de Popper, sino como un enriquecimiento de la visión excesivamente simplificada del método científico que tal metodología proporcionaba. Sin embargo, por influencia de algunos discípulos de ambos, la obra de Kuhn ha tendido a utilizarse sobre todo para imprimir un giro historicista a la teoría de la ciencia. Al igual que en nuestras disciplinas la crítica antipsiquiátrica jugó un importante papel de tipo historicista y político-crítico (94-98), de la misma forma y coetáneamente toda una oleada irracionalista sacudió casi los cimientos de la epistemología. Sólo en el último decenio puede observarse una cierta recuperación y aprovechamiento creativo de tales tempestades: en nuestros lares, la obra editada por Olivé en 1995 (68) puede ser una buena muestra de ello. El resultado es una especie de concepción post-kuhniana de la racionalidad científica. Dicha concepción poseería las siguientes características, recogiendo, ampliando y sistematizando las aportaciones de Quintanilla (78-81):

1. Ejemplaridad: La ciencia se sigue tomado como modelo ejemplar de la racionalidad epistémica, --y, en consecuencia, de conocimiento racional-- pero asumiendo un modelo empírico y no sólo lógico de la ciencia y el conocimiento científico.

2. Pero el modelo de la ciencia es de carácter procedimental: lo modélico es el procedimiento, no el contenido o el grado de aproximación a una supuesta Verdad nunca alcanzable. La ciencia busca la verosimilitud de nuestras teorías y modelos sobre la realidad, más que la Verdad. El conocimiento científico es nomotético, pero la ciencia como empresa no lo es: no hay un sistema de reglas que, aplicadas mecánicamente, permita definir el contenido de la racionalidad epistémica. La racionalidad es más un asunto de comunicación y discusión colectiva, así como de los criterios para mantener y cerrar tal discusión, que de aplicación mecánica de las reglas. Los métodos científicos no garantizan un resultado seguro, pero obligan a seguir buscando soluciones racionales a los problemas a los cuales se aplican.

3. Pluralidad: Durante períodos más o menos largos, enigmas, problemas y anomalías pueden recibir respuestas plurales, todas ellas plausibles. Lo irracional no es que haya diferentes ideas o teorías en la ciencia; lo irracional sería que sólo existiera una. 
Creo que la epistemología anarquista de Feyerabend ha jugado un importante papel en la radicalización y difusión de estas posturas.

4. Capacidad de tolerar la novedad y las opiniones minoritarias: Cada vez está más claro que lo que mide la capacidad creativa de un paradigma y de una comunidad científica es su capacidad de acoger, integrar y tolerar las posturas discrepantes y minoritarias ${ }^{3}$.

5. Diacronía: la racionalidad requiere tiempo. No se adoptan decisiones racionales sobre la verosimilitud y el valor de una teoría, un modelo o un paradigma sino después de largas y arduas controversias y choques de perspectivas.

6. Creatividad o producción de novedad: es el criterio y orientación básica de la actividad científica. Investigar es, ante todo, crear nuevos conocimientos, crear formas de aprehender y manejar situaciones y problemas nuevos e imprevistos (Muguerza 1975, 65).

7. De las cuatro últimas características cabe deducir el carácter polémico del conocimiento científico: el modelo científico no es el del discurso axiomático, sino el del debate académico, los diálogos científicos y las diatribas sofísticas. En esencia, no es una búsqueda de acuerdos, sino una explotación de la capacidad creativa de los desacuerdos y la polémica. De ahí que el eclecticismo, apto e incluso necesario para la técnica, para el artesanado, para el ecumenismo o para la filosofía, no suele ser útil para el desarrollo científico.

8. Los procedimientos y sistemas tecnológicos, considerados en tanto que "conjuntos de acciones, orientados a la trasformación de objetos --o sistemas--, para conseguir de forma eficiente resultados que se consideran valiosos" (Quintanilla 2000, 79-81) suponen también paradigmas de la acción racional, similares a los científicos. Máxime si en su consecución se utilizan los diferentes métodos de al ciencia.

Como puede observarse, no son esos los criterios en cuanto a la cientificidad dominantes en nuestras disciplinas de la salud mental. En ese sentido, hemos de afirmar que en la epistemología interna de nuestras disciplinas hasta hoy la "trasformación kuhniana" no ha entrado ni con siquiera una mínima profundidad. De ahí que algunos estemos interesados en ese replanteamiento de la epistemología de nuestras disciplinas, replanteamiento que incluya la sociología, la sociología histórica y la psicología de la búsqueda de la racionalidad científica en las mismas (13-15, 19, 46-49, 119-124, 126). Algo que en la epidemiología han intentado, por ejemplo, autores como Marmot (58-59), Mcintyre o Epstein (24). ¿Cómo se comportan los científicos y comunidades científicas de nuestras disciplinas en su supuesta búsqueda de la racionalidad científica, en su búsqueda de conocimientos verificables, falsables, apofánticos y no contradictorios con otras ciencias?. ¿Cómo buscan nuestros tecnólogos-si lo hacen-las cualidades de nuestras empresas, sistemas y procedimientos técnicos, tales como las cualidades de las terapias señaladas en la tabla 1 , reformulada a partir de $44 \mathrm{y}$ 122-123?. 


\section{Las disciplinas de la salud mental: Un} mundo constitutivamente interdisciplinario.

Aceptemos momentáneamente esa perspectiva de lo que un paradigma puede ser y significar. En ese sentido, siguiendo el planteamiento de las XVIII Jornadas de la Asociación Española de Neuropsiquiatría (Huelva 2002): ¿Cuál es el paradigma dominante en la Psiquiatría? ¿Ha cambiado en los últimos treinta años? Parecería una pregunta clara y relevante, pero en mi opinión, encierra ya un problema y una discusión epistemológica de base.

En efecto: el primer paso del desarrollo de la psiquiatría, como en muchas otras ciencias, fue un estadio descriptivo. Ese primer paso se consolidó con la delimitación de los primeros síndromes en los trabajos de Pinel, Esquirol, Georget... Más tarde, el descubrimiento de correlaciones biopsicológicas profundizará la medicalización de la naciente disciplina: si anteriormente se había intentado, según el modelo médico, una clasificación a partir de los síntomas, agrupados en síndromes, ahora se intentará el diagnóstico anatomopatológico y la "psiquiatría anatomo-patológica”. El descubrimiento inicial lo realizar Bayle en la "parálisis general": demuestra su vinculación con las lesiones meníngeas crónicas. Cuatro años después, la medicalización con el modelo anatomopatológico se muestra patente en su libro "Tratado de las enfermedades del cerebro y sus membranas". Sin embargo, el modelo, a pesar de haber recibido la sanción positiva de la ideología dominante durante más de dos siglos, no resulta tan fructífero como sus primeros logros hacían prever.

A pesar del fracaso (relativo) de las iniciales perspectivas sintomáticas (descriptivas) y de las anatomopatológicas, en la Psiquiatría, e incluso en el conjunto de las disciplinas de la salud mental, ha persistido siempre la influencia dominante del modelo médico y, por lo tanto, la tendencia al reduccionismo biologista, aunque éste sufrirá una reconversión en función del desarrollo de la medicina de cada época. En estas reformulaciones el primer éxito vuelve a obtenerse también a partir de la "parálisis general", cuando en 1906 Wassermann por serología, y más tarde, Noguchi y Moore, logran demostrar la existencia del "treponema pallidum" en una importante proporción de los sujetos afectos de tal "parálisis". El camino parece al principio muy prometedor y pronto proliferan supuestos descubrimientos etiopatogénicos sobre el origen de los diversos trastornos mentales. Sin embargo, hasta hoy el recorrido no resulta demasiado cargado de éxitos, pero demuestra precisamente por ello hasta qué extremo el modelo y los conceptos médicos y la epistemología físicobiológica han dominado la psiquiatría hasta nuestros días: en el siglo XIX las obras de J.P. Falret, de Ritt, Lasègue, Baillarger, Morel, Magnau, Moreau de Tours, Kahlbaum, Kraeplin, etc son hitos en la historia del desarrollo de la psiquiatría como disciplina médica.

Los lazos entre la Psicopatología y Psiquiatría nacientes y la Medicina (o Biología Humana, no lo olvidemos) se desarrollarán pues de forma fundamental en el siglo XIX, aunque es también hacia finales del XIX cuando se abre la vía de 
influencia decisiva de la psicología en la psiquiatría. Con el desmoronamiento del edificio biomédico de Charcot sobre la histeria, todo un conjunto de autores va a profundizar en la perspectiva o paradigma psicológico de la psico(pato)logía, que ya había sido aventurado por Parecelso e Hipócrates a propósito de la histeria: Es lo que harán, por un lado, los propios discípulos de Charcot (Binet, Freud, Ribot, Babinski y Janet), ajustando cuentas con su maestro. Pero también es lo que harán, aunque con una versión divergente, inaugurando nuevos paradigmas, dos autores con gran influencia en el futuro de la psiquiatría y la psicología: S. Freud y J. Watson. En ese sentido, como hace años vengo defendiendo, el psicoanálisis, a pesar de las inclinaciones hacia el reduccionismo biologista de su fundador, va a ser el primer intento totalizador y comprehensivo del estudio de la psico(pato)logía y la psiquiatría con modelos psicológicos. A partir de entonces vamos a asistir a la complejificación y desarrollo de tales modelos en la psicopatología y la psiquiatría.

Sin embargo, durante el siglo $\mathrm{XX}$, los lazos que se habían entretejido con otras ciencias se multiplican y aparecen nuevas relaciones inesperadas. Con la física, la psiquiatría pronto va a tener en común todo el campo del estudio neurofisiológico de los trastornos mentales (electroencefalograma, potenciales evocados, poligrafía, TAC, PET...) y algunas formas de terapia, hoy más o menos abandonados (hidroterapia, faradizaciones...) o "reflorecientes" (electroshock, helioterapia...). A la química, y en particular a partir del descubrimiento de los primeros fármacos antipsicóticos por Delay y Deniker, en la década de los cincuenta, la psiquiatría va a deberle el desarrollo del la psicofarmacología, que abrió una nueva vía, indudablemente fecunda, en el tratamiento e incluso en la comprensión tecnológica de los trastornos mentales.

Posteriormente hemos podido asistir a la introducción en psiquiatría de las ciencias formales y las ciencias sociales. Durante decenios, esta influencia ha sido frenada precisamente por el predominio abusivo de los modelos médicos y del reduccionismo biologista. Hoy, sin embargo, las necesidades de investigación técnica (en psicofarmacología) y comercial (en estudios de marketing, más o menos encubiertos bajo ropajes seudocientíficos) han abierto una brecha para la formalización en psiquiatría. Pero, al contrario de como esperaba en 1978, no puede decirse que esa introducción de las ciencias formales haya llevado a una crítica del estrecho empirismo y biologismo de buena parte de la psiquiatría contemporánea, de sus técnicas y de sus métodos de estudio e investigación, al menos hasta el presente (20, 46-48): Por el contrario, el predominio abrumador del biologismo ha llevado a una utilización de la matematización y formalización precisamente al servicio de una forma de empirismo reduccionista: el biologismo u organicismo, substrato común de la "psiquiatría biológica" y la "psiquiatría ateorética" tan en boga últimamente.

De todas formas, sigo pensando, como ya hacía en 1978, que es posible un replanteamiento de la epistemología positivista y empirista iniciales de la mano de las perspectivas cognitivistas y 
psicodinámicas. Y que esa brecha puede seguir ampliándose: la cibernética y teoría de sistemas, así como la teoría de la comunicación o las disciplinas de la "inteligencia artificial" pueden pasar a jugar un papel mucho más relevante en la teorización, la investigación y la práctica psiquiátrica contemporánea y futura.

En los últimos años, sin embargo, parece que las ciencias sociales se han quedado atrás en su penetración en el atrincherado edificio de la psiquiatría, al menos de la psiquiatría académica: hasta el extremo de que hoy, hablar de sociogénesis de los trastornos mentales o plantearse investigaciones en ese sentido, o sobre la sociología de nuestras disciplinas, es tan excepcional que a veces he dicho que pueden parecer manifestaciones de una "especie sesentaiochesca en vías de extinción”. A pesar de todo, como veremos más adelante, su influencia se deja sentir ya no tan sólo en el nivel conceptual de la psicología, la psicopatología y la psiquiatría, sino también en el nivel "epistemológico interno y derivado": sí que se han propuesto nuevas hipótesis y modelos basados en la sociología, la antropología, la etnología, la ecología, la teoría de la comunicación... (20-26). El problema es que, nuevamente, tales potencialidades a menudo quedan perfectamente "digeridas" dentro del "conglomerado organicistaindustrial" y desvirtuadas en sus potencialidades trasformadoras en lo teórico y en lo asistencial.

Por tanto, una tendencia esencial en la psiquiatría y la psicopatología, desde su aparición como ramas científicas, es la tendencia a la reducción de los hechos comportamentales a hechos neuro- fisiológicos, reduccionismo epistemológico que da lugar a las explicaciones llamadas "organicistas". Ya desde hace años vengo ocupándome del organicismo como una forma de reduccionismo biologista. Esa es la forma que ha predominado hasta los últimos decenios del siglo XX. Sigo definiendo el reduccionismo biologista como lo hicimos ya en 1986 desde el punto de vista epistemológico: "la extensión-generalización abusiva de explicaciones y modelos biológicos al campo de otras ciencias y tecnologías (en particular, al campo de las ciencias psicosociales) sin que dicha extensión o generalización proporcione otros beneficios o se apoye en otros argumentos que los meramente ideológicos (no contrastables ni verificables)" (tabla 2). Hacia finales del siglo XX, sin embargo, el reduccionismo biologista parece que adoptó una nueva forma, claramente reduccionista hasta en sus términos: el reduccionismo hacia las neurociencias. De ahí el título de esta comunicación y este trabajo: ¿Por qué "neurociencias" y no "psicociencias"? Es evidente el enorme desarrollo que ha sufrido la neurología -no tan enorme en el plano terapéutico- y el asimismo impresionante desarrollo de la psicofarmacología - no tan enorme en el campo teórico, desde luego. De ahí que sea fácil entender este renacido imperialismo de lo neurológico, que tanto recuerda al de los últimos años del siglo XIX y las perspectivas neurológicas sobre la histeria y las neurosis. Pero esta vez con modelos, técnicas y conocimientos remozados con respecto a lo ocurrido a finales del XIX y principios del XX. Los avances, tanto reales como supuestos, son 
tan impresionantes, que ha comenzado a hablarse de las neurociencias, como un nuevo capítulo científico que, por supuesto, englobaría la psicología, la psicología clínica, la psicología y la psicopatología del desarrollo, las técnicas de psicoterapia, y, en general, todo el continente psicológico. Esta reducción de lo psicológico a lo neurofisiológico es piedra de toque en la psiquiatría actual y afecta al nivel pragmático, al nivel conceptual, al nivel de epistemología interna (reduccionismo) e incluso al nivel de epistemología derivada de la psiquiatría contemporánea: por ejemplo, con ese reduccionismo es difícil evadirse de los problemas y malestares que el "paralelismo heurístico y pragmático" plantea al poner en relación los hechos de conducta y la secuencia fisiológica. Aquí, como en otros campos, parece que Godzilla (el reduccionismo biologista) está resultando mucho más poderoso que la "indefensa" Bambi (la psicología en tanto que ciencia de la conducta significante, de la comunicación, de la relación interpersonal e interna, mucho menos mecanizada y mecanizable...).

Pero, tal vez desgraciadamente, vuelve a tratarse aquí de un fenómeno más magnificado que real, más ideológico que científico, más determinado por el efecto Utah que por la medicina y la psiquiatría basada en las pruebas $(86,124)$. Como decía, creo que los apoyos para esa hipérbole de lo neurológico son los siguientes:

a. El desarrollo de la neurología, que hoy ya permite mostrar la "unidad psicosomática" y las bases de numerosas reacciones psicológicas desde la propia neurología y la neurología del desarrollo $(1,2,18-23$, $55,69,70,75 \ldots)$

b. El desarrollo de la psicofarmacología, desde Delay y Deniker hasta nuestros días.

c. El poder económico de la industria química.

d. Las amplias perspectivas económicas que abre la psicofarmacologización de la vida cotidiana.

e. Los poderes ideológicos puestos en marcha por esas realidades científicas y esos poderes económicos.

f. La facilitación seudocientífica de la teoría que proporciona pues ese reduccionismo.

g. La simplificación teórica de la medicina contemporánea (de la biopsicosocial a la biosocial: 18,23-26, $39,104)$ y la psiquiatría: desde una especialidad holística, biopsicosocial, apoyada en la búsqueda de una teoría del sujeto, hacia una especialidad parcializada, reduccionistamente biológica, dominada por un criterio de adaptación social.

En definitiva, con una perspectiva más amplia, en la psiquiatría y la psicopatología podríamos perder la posibilidad de seguir enriqueciéndonos a todos los niveles de las relaciones complejas entre Ciencias Biológicas, Psicológicas y Sociológicas: esa encrucijada de relaciones que para mí, en 1978, constituía su posición específica, potencialmente pluralista y creativa. Pero, por causa de motivaciones epistemológicas $\mathrm{y}$, en último extremo, de motivaciones relativas al poder económico e ideológico, en realidad a menudo esa posición "en la encrucijada" ha dificultado históricamente la consecución de un paradigma unificador en el seno de nuestras disciplinas. 
Con esa compleja historia detrás, $\mathrm{y}$ teniendo en cuenta su fundamento científico plural, ¿cómo podríamos encuadrar a la psiquiatría y psicopatología actuales en una clasificación de las ciencias y disciplinas científicas, por ejemplo según el modelo circular de la clasificación de las ciencias $(71,72)$ ? En 1978 defendí que la psiquiatría ha de definirse o bien como la disciplina médica que estudia y trata a las personas que exhiben conductas anómalas o trastornadas (una especie de "psicopatología médica" acompañada de técnicas terapéuticas) o bien como la tecnología --conjunto de conocimientos científicos y de recursos y medios técnicos-- del tratamiento de dichos trastornos --la psico(pato)logía aplicada.

Con la primera opción, difundida sobre todo por los partidarios de una psiquiatría y la psicopatologías medicalizadas, se mantiene la inclusión de la psicopatología y la psiquiatría dentro del ámbito de la medicina, como ramas de la biología humana, como un campo del conocimiento biomédico. Mi opinión actual en este dilema es clara y difiere de la que mantuve en 1978. Me parece que hoy por hoy la psiquiatría no puede ser "desmedicalizada": tanto porque las terapias psicológicas han alcanzado ya una clara independencia con respecto a la psiquiatría --que, en todo caso, debería sentirse obligada a demandar su concurso-como por la realidad de que la propia medicina y la atención sanitaria desean ampliar su perspectiva teórica y epistemológica en la vía biopsicosocial, descartando parcialidades reduccionistas tales como el biologismo. Es decir, que nos encontramos con la aparente paradoja de que, mientras que las demás ramas de la medicina intentan incorporar como programa de investigación fundamental el paradigma biopsicosocial, al menos a nivel teórico y de declaración de intenciones, la psiquiatría ha realizado una evolución opuesta: de postularse como la más globalizadora, holística o antropológica de las especialidades médicas, a postularse como una rama de la biomedicina o, más biologistamente aún, como una técnica del ámbito de las neurociencias. Lo cual implica al menos dos tipos de problemas teóricos y epistemológicos: el primero, nos lleva de nuevo al título de esta ponencia. ¿Por qué "neurociencias" y no "psicociencias"? Al hablar de "neurociencias" a menudo no nos percatamos que de que estamos haciendo más que una metáfora, una sinécdoque en el vacío, un "brindis al sol": la psicología como ciencia implica una serie de disciplinas científicas y tecnológicas diferenciadas (psicología evolutiva, psicopatología, psicología diferencial, psicometría, psicoanálisis...), mientras que la neurología (y la "neurociencia") es una parte de la biología. Difícilmente un conjunto puede englobarse dentro de una parcialidad, máxime cuando esa parcialidad forma parte de un ámbito epistemológico diverso (7-11, 71-74).

Pero el segundo tipo de problemas proviene incluso del propio término de "neurociencias". ¿Por qué "neurociencias" y no "neurotécnicas"? Menos humorísticamente: ¿la psiquiatría y sus especializaciones pueden catalogarse como disciplinas fundamentalmente científicas o fundamentalmente técnicas? ¿Cómo "ciencias" o como "técnicas" ? 
4. Psiquiatría: ¿Ciencia, tecnología, técnica, artesanía clínica? .

La segunda opción añade una caracterización estrictamente epistemológica de la disciplina psiquiátrica: creo que hemos de pasar a considerar a la Psiquiatría como una técnica, en el mejor de los casos con elementos tecnológicos, basada en una serie de conocimientos teóricos proporcionados por diversas ciencias (aplicadas, como la medicina, o "puras" como la psicología) y una serie de instrumentos y recursos técnicos propios de otras ciencias aplicadas y tecnologías: química aplicada, psicología clínica y psicoterapia (108-121), física aplicada, psicosociología, etc. Si se tratara de una ciencia, su circuito básico de investigación sería el científico: descubrir la teoría $T$ que explique los acontecimientos $A$ en determinadas circunstancias $C(A-C-T)$ : tabla 3 . Pero es fácil observar cómo, en realidad, gran parte de sus rompecabezas, enigmas y problemas de investigación tienen que ver con el circuito del conocimiento tecnológico: dada una teoría (biológica, psicológica o sociológica), buscar las condiciones para que se produzca una acontecimiento deseado (T-C-A) (tabla 4). Y, hoy por hoy, las condiciones que se buscan son fundamentalmente las biológicas. A menudo, el viaje es tan corto que no se necesitan teorías procedentes de ninguna ciencia de base, salvo de la propia biología -y, como mucho, de la mercadotecnia.

Las razones para ello no sólo son teóricas y epistemológicas, sino también prágmáticas: casi no es necesario insistir en el hecho de que la mayor parte de la actividad de la mayor parte de los psiquiatras se consume hoy en el circuito técnico y artesanal y sólo muy ocasionalmente, y si se cumplen determinadas condiciones de trabajo y objetivos de estudio, en el circuito tecnológico. Pero para hacer ciencia, realmente ciencia en el sentido más actual del término, el psiquiatra casi siempre ha de dejar de hacer de psiquiatra y pasar a trabajar como biólogo del cerebro humano, bioquímico, psicólogo, psicosociólogo... Y mucho más aún el así llamado "psiquiatra clínico", cuya actividad fundamental es la aplicación de una serie de técnicas utilizando para ello su "buen hacer" artesanal en el auxilio de los seres humanos en conflicto.

El por qué un hecho tan evidente no es tomado casi nunca en consideración habría que buscarlo fuera ya de las propias disciplinas. Nos moveríamos entonces en el terreno de las opciones concretas de la ideología dominante (y en este caso, de una de las fundamentales: el biologismo) y en el terreno de las relaciones de producción: la así llamada "clase médica" necesita "santificar" continuamente su puesto antes privilegiado y hoy en franco declive en el seno de las formaciones económicosociales "desarrollistas". ¡Y qué mejor hagiografía en nuestros días que la científica, cuando se ha derrumbado el prestigio social de otras fórmulas hagiográficas! La especialización de la psiquiatría parece ser una de las que más ampliamente ha recibido el impacto de la "nueva proletarización" de los especialistas médicos. Y encima, antes de que llegara a constituirse realmente como "disciplina médica". Creo que esa es otra de la razones del gran interés que muchos de los prohombres de nuestra disciplina muestran 
por exhibir exploraciones, predictores, pruebas complementarias, tratamientos y teorías "bien biológicas": para que la disciplina pueda ser considerada claramente como una "especialidad médica".

Un buen resumen de las discusiones acerca de la diferenciación entre actividad científica y actividad tecnológica puede encontrarse por ejemplo en Quintanilla (78-81). Aquí creo que, para tratar esquemáticamente al menos el tema, tendríamos que comenzar con recordar la premisa básica de que la actividad científica se orienta hacia la búsqueda de saberes o verdades cada vez más exactos o profundos, de modo formalmente independiente del uso que tales saberes pueda tener en el presento o en el futuro. En cierta manera, se trata de un saber por saber, de una expresión, posiblemente la más directa, de lo que los psicoanalistas llamamos pulsión epistemofílica (M. Klein) o vinculo de conocimiento (W.R. Bion). La actividad tecnológica, por el contrario, va orientada a solucionar problemas concretos (por ejemplo, problemas psicopatológicos). Ahora bien: en el marco de esta actividad, si está regida por sistemas y métodos científicos (fundamentalmente verificables y contrastables), surgen de continuo datos, procedimientos y teorías incluíbles dentro del corpus científico.

Desde el punto de vista formal, un sistema técnico podrá definirse por la expresión siguiente:

$$
T=<C, S, S^{l}, A, A^{l}, O, R>
$$

En este sistema técnico,

$C$ es un conjunto de sistemas concretos que constituye los componentes o materiales de $\mathrm{T}$.
$S$ es un conjunto de agentes o sujetos humanos capaces de actuar intencionalmente sobre elementos $C \mathrm{U} S$.

$\underline{\text { A }}$ es un conjunto de acciones definido en $C \mathrm{U} S$.

La estructura $A=<C \mathrm{U} S, A, R>$ constituye un Sistema de Acciones con resultado $R$.

La estructura A ' $=\langle S, S$ ', $A, A$ ', $O, R>$ constituye un Sistema intencional de acciones.

Por tanto, desde el punto de vista formal un sistema tecnológico (o tecnología) "es un sistema de acciones planificadas algunas de las cuales utilizan artefactos como instrumentos" (Quintanilla, 1981). Y recordemos que los artefactos no son solamente las máquinas. Desde el punto de vista psicoanalítico podría considerarse, por ejemplo, que el encuadre, marco o setting de la atención es, en cierta forma, un artefacto intencional (con respecto a la relación humana no profesionalizada). La práctica efectiva de la psiquiatría se compone habitualmente de dos elementos fundamentales: un repertorio de conocimientos y un conjunto de prácticas (sistemas de acciones) organizados para conseguir los resultados más eficaces y eficientes (pero también más aceptables socialmente). Las tecnologías no son solamente ciencia aplicada, sino prácticas de aplicación de la ciencia. Y casi nunca existe una sóla forma de aplicar un conocimiento, sino muchas alternativas tecnológicas....

De acuerdo con los planteamientos de Bunge (8-11), en la investigación o desarrollos tecnológicos las circunstancias o condiciones empíricas se verán restringidas por el interés práctico 
de la investigación (o por condicionamientos materiales de otro tipo: por ejemplo, económicos), mientras que se supone que en la investigación "pura" no hay más limitaciones que las inherentes al estadio de desarrollo de la ciencia y la creatividad de los científicos. Desde esta perspectiva, por tanto, podría decirse que, en primer lugar, es inherente a las leyes científicas el que puedan servir de base a las tecnológicas. Segundo, que, como ya hemos visto anteriormente, existe una estrecha similitud estructural entre la investigación científica y la tecnológica. Tercero, que los resultados de ambos tipos de investigación se diferenciarán más a nivel cuantitativo, de grado (generalidad, precisión, grado de abstracción y validez universal, etc.) que por la propia estructura epistemológica de cada tipo de investigación o práctica.

En el tema que nos ocupa por ahora basta con señalar que, desde le perspectiva de Kuhn (1962), una buena parte de la llamada "ciencia normal" puede estar formada por la investigación, el desarrollo y las aplicaciones tecnológicas del paradigma dominante. Cuando Lakatos (1970) habla de programas de investigación progresivos y regresivos considera que un programa es progresivo si su desarrollo teórico anticipa su desarrollo empírico; es regresivo o degenerativo si tan solo puede desarrollarse mediante continuas readaptaciones, retoques e hipótesis ad hoc. Siguiendo a Lakatos podemos observar cómo, en la práctica real de la historia de la ciencia, puede advertirse una clara conexión entre los momentos de investigación pura y de desarrollo o aplicación tecnológica: en nuestra acepción de qué son los programas de investigación tal vez convendría incluir ambos aspectos, en realidad inextricablemente imbricados. Pero los componentes extracientíficos que se dan en la aplicación tecnológica de la ciencia (por ejemplo, en cuanto a la fijación de los objetivos) siguen quedando fuera del foco de atención del metodólogo. J.D. Bernal (1964) había intentado una aproximación al tema, pero con el tiempo y los cambios sociales e ideológicos en los países industrializados, su perspectiva ha quedado reducida a un mero intento aproximativo hoy casi olvidado (6).

Una consecuencia de esta perspectiva de la tecnología para el caso de las tecnologías psicológicas y psiquiátricas (de exploración o estudio y de intervención) es que la tecnología puede proporcionar conocimientos útiles para la ciencia, e incluso para las ciencias "puras". En el caso de algunas Técnicas de Psicoterapia, su perspectiva científica y su orientación de cara a proporcionar tales conocimientos científicos de tipo general son evidentes y explícitas: Freud, Watson, Kelly, Skinner, etc., han trabajado en el campo de las Técnicas de Psicoterapia de forma tecnológica, con la perspectiva pragmática de la eficacia y eficiencia, al tiempo que con la perspectiva epistemológica de proporcionar conocimientos científicos. Algunas orientaciones de la Psiquiatría y la Psicoterapia hacen explícito además su interés por basarse en el método "científico" en sus aproximaciones e incluso prácticas: la investigación psicofisiológica y neurológica, todas las aproximaciones conductistas o basadas en la psicología del aprendizaje, una parte del 
psicoanálisis contemporáneo, numerosas metodologías psicoterapéuticas de corte cognitivista, etc.

Queda claro, pues, que, desde este punto de vista, lo que en último término diferencia a la tecnología en general de la ciencia en general es lo que Bunge ha llamado "las restricciones que el tecnólogo debe soportar en su investigación", restricciones de todo tipo que se hacen relevantes frente a la supuesta libertad y falta de límites externos con las que, en principio, podría trabajar el científico. Pero, como es fácil de advertir, tal diferenciación en muchos casos no pasa de ser meramente ideológica, ya que las limitaciones institucionales y de todo tipo a la "ciencia pura" son lo habitual en el desarrollo de la misma; o lo que es lo mismo: todo programa de investigación está limitado pragmáticamente. Por ejemplo, en la psiquiatría actual es patente cómo la limitación de presupuestos para la investigación es mucho más notoria para los programas de investigación psicológicos o psicosociales y mucho menor para los programas organicistas (122-123). He ahí nuevamente otro ejemplo de la importancia de las perspectivas institucionales e históricas del estudio de la ciencia, tales como las propuestas inicialmente por Bernal en 1964 (6) y, posteriormente, por Kuhn, Feyerabend, Lakatos y otros muchos epistemólogos.

Lo anterior corrobora mi posición contraria a la conceptualización de la psiquiatría como una ciencia o disciplina científica: en la mayor parte de nuestro trabajo cotidiano como clínicos, e incluso en los momentos o programas de investigación --sobre lo individual o sobre lo general-- no buscamos precisamente las teorías y modelos que expliquen los acontecimientos; nuestras predicciones de los mismos vienen profundamente marcadas por necesidades pragmáticas, más que por un afán de conocimiento científico. Mi opinión es que, en la psiquiatría actual existen grupos, programas y momentos de investigación científica pero que, desde luego, no son los dominantes en su desplegamiento como disciplina.

Tampoco puedo quedarme tranquilo con la acepción opuesta, que consideraría a la psiquiatría como un mero arte o artesanado: y no por prejuicios elitistas o intelectualistas, según los cuales el trabajo "intelectual" y/o "profesional" es un trabajo de rango superior o más excelso por oposición al trabajo "manual", "asalariado" o "artesano". Al contrario, mi intranquilidad proviene de los peligros que para cualquier arte o artesanado conlleva la ruptura de ligámenes con empresas siempre en movimiento como son la ciencia y la tecnología. A menudo, es cierto que la práctica psiquiátrica y psicoterapéutica está dominada por elementos artesanales, puede convertirse en un mero artesanado --salvo para los clínicos con la habilidad y sensibilidad suficiente, en los cuales ese "artesanado" puede ser admirado como un verdadero "arte". Pero la relación con la teoría y "marco de referencia" y la absorción --o experimentación-- de nuevas técnicas y procedimientos procedentes de la ciencia y la tecnología han de promover una continua tensión en su práctica que impida la mera repetición artesanal, por "oficio aprendido". Además, si la psiquiatría puede hallarse abierta a las perspectivas 
científicas contemporáneas, sus aproximaciones pueden incluso proporcionar conocimientos enriquecedoras para el conjunto de la ciencia y la tecnología: por ejemplo, conocimientos acerca del comportamiento y las representaciones mentales anómalas o trastornadas y, por tanto, acerca de las leyes de desintegración del aparato informacional al que llamamos "mente"; o por ejemplo, acerca del valor y leyes de regulación de las relaciones entre el individuo humano y las redes sociales...

En este sentido recordemos cómo el llamado "arte clínico" (e incluso el llamado "ojo clínico") del antiguo médico de cabecera están siendo reconsiderados desde la perspectiva tecnológica: por ejemplo, desde puntos de vista basados en la Inteligencia Artificial y los modelos simulativos. O desde la teoría de la atención sanitaria centrada en el consultante (25-26, 90, 101-104). O desde la posibilidad de investigación de los elementos relacionales que favorecen ese "arte clínico" del médico de cabecera o psiquiatra en nuestras formaciones sociales...

En definitiva, en mi opinión, ese conjunto técnico-tecnológico que sería pues la psiquiatría, interdisciplinar con predominio biológico, orientado al estudio y tratamiento de los trastornos mentales, puede ser considerado una disciplina técnica con elementos y momentos tecnológicos. En su necesidad de orientación como tecnología, con el fin de no regresar en su práctica al mero artesanado, importan por un lado la creación y realización de grupos y programas de investigación realmente autónomos orientados con los métodos y modelos de la ciencia. Pero también importa que el trabajo clínico concreto, los momentos de arte y artesanado, puedan estar influenciados y organizados, en la medida de lo posible, por el algoritmo de la ciencia y por los diversos métodos científicos. Ello no quiere decir que se utilicen tan sólo ese algoritmo y/o esos métodos, sino que nuestra aproximación a nuestros "objetos de conocimiento" (los supuestos "trastornos mentales" de unos seres humanos concretos) ha de estar mediatizada y organizada, amén de por unos principios éticos elementales, también por el algoritmo y métodos de la ciencia. Y de esta forma, determinados clínicos honestos en su deseo de conocimiento y ayuda del consultante, si utilizan, en la medida de lo posible, técnicas observacionales rigurosas $(1,88)$ informadas por las pruebas científicas existentes, por la epidemiología y por teorías actualizadas, pueden resultar mucho más "científicos" o "tecnólogos" que otros, dedicados a la realización de estudios de marketing encubiertos bajo excelsos instrumentos estadísticos, metodológicos o mecánicos.

Por lo tanto, más que ahogarnos en un estudio de demarcación (¿es técnica o tecnología la práctica clínica o metodológica que realizamos?) convendría definir qué condiciones permiten transitar en ambos sentidos del camino ciencia -tecnología - técnica artesanado - arte. Parece que las más señaladas por la moderna epistemología de la tecnología son las condiciones de efectividad, replanteamiento continuo y complementariedad con otras ciencias y tecnologías contemporáneas (79). 
Esas tres condiciones generales para la consideración de una actividad psiquiátrica como tecnología (o como "técnica con referente científico") podrían desglosarse en una serie de normas o condiciones epistemológicas consustanciales a esa consideración metateórica. Esquemáticamente desarrolladas, tales criterios serían aproximadamente los siguientes:

1) Toda tecnología está regida por el principio de optimización o maximización de los resultados. Dicho en otros términos, por el intento de aumentar su eficacia, efectividad, eficiencia y accesibilidad, oportunidad, etc (44, 117, 119-124: tabla 1). En este sentido, los "tratamientos" únicamente orientados al aumento del "autoconocimiento", tales como determinados métodos experienciales o humanísticos, ciertas versiones del psicoanálisis o diversas formas de meditación, difícilmente podrían encajar en el acerbo de las técnicas estrictamente psiquiátricas.

2) La condición de la innovación constante, propia de todo sistema tecnológico, proporcionaría también interesantísimas reflexiones en nuestro ámbito. Por ejemplo, limitaría la reacción de "escándalo" y "desaprobación" por parte de muchos científicos y estudiosos al enfocar las continuas discusiones y disensiones entre autores y escuelas de psicoterapia. El principio de la epistemología "anarquista" de Feyerabend (1970) del todo vale es, si cabe, más aplicable aún en el campo de la tecnología que en la ciencia. En efecto, para un tecnólogo consecuente, con las limitaciones éticas y materiales previas, todo vale, es decir, cualquier innovación debe ser probada con tal de optimizar los resultados. Esa apreciación situaría además las posturas de "escándalo" ante disensiones, discusiones y divisiones entre psicoterapeutas fuera del ámbito científico $-\mathrm{y}$ mucho más porque son más explicables en unas tecnologías que afectan a lo humano, que afectan a personas, que están basadas en la relación $\mathrm{S}<-->\mathrm{O}$ de conocimiento.

3) El principio de compatibilidad con la ciencia coetánea ha sido considerado también, siguiendo a Bunge (1980), como fundamental para toda tecnología y, por lo tanto, para la psicopatología y la psiquiatría en tanto que conocimientos tecnológicos. Ello significa que no deberíamos, con justeza, aplicar el calificativo de "técnicas psiquiátricas" a los procedimientos de cualquier tipo incompatibles con la ciencia coetánea o por principio no controlables (comunicables y verificables) mediante alguna de las metodologías científicas normalmente utilizadas.

4) Como hemos visto, toda tecnología implica la utilización de artefactos. La consideración de los "artefactos" es más difícil de apreciar desde el mero "sentido común" en el caso de las que hemos llamado "tecnologías basadas en conocimientos operacionales" y en las "tecnologías sociales"(111,112): ello confiere a las técnicas biológicas de la psiquiatría una indudable "posición de ventaja" con respecto a otras técnicas --menos avaladas, además, por el poder médico, industrial 
y académico. Pero desde el punto de vista teórico hay que considerar que, como poco, el llamado marco, encuadre o "setting" de cada técnica terapéutica es en sí mismo un artefacto. Más aún: no es posible practicar una técnica sin algún tipo de "artefacto", por lo que las visiones exclusivamente "interpersonales", "experienciales" o "humanísticas" de la psiquiatría y la psicoterapia difícilmente podrían recabar para sí el calificativo de "técnicas". Item más, ello implica la necesidad de definir con la mayor precisión posible ese encuadre o marco para que pueda hablarse de práctica tecnológica.

5) Una condición más de la estructura de la tecnología es la combinación en la misma de enunciados nomológicos con enunciados nomopragmáticos, algo sumamente visible en cualquier técnica psiquiátrica y que, en ocasiones, deriva en una confusión entre la técnica, la teoría de la técnica y la teoría psicológica que le sirve de base. El psicoanálisis es un buen ejemplo de esas discusiones y esas dificultades 6) como cualquier otra tecnología, la psiquiatría y, más aún, las técnicas de psicoterapia, se están convirtiendo en una fuente importante del conocimiento (y construcción) de la realidad: a menudo, la psicopatología ha sido una derivación de la psicoterapia y no a la inversa. Es el caso, por ejemplo, de la psicopatología psicoanalítica o, en buena medida, de clasificaciones supuestamente más empíricas (y, desde luego, más biologistas) como la DSM-III y DMS-IV americanas. En este sentido, $\mathrm{y}$ en otros muchos que no podemos tratar aquí, las investigaciones psicofarmacológicas y en diversas técnicas de psicoterapia se han convertido en importantes fuentes de conocimientos no sólo para la psicopatología, sino para la psicología en general (20, 46-50, 82-85, 91-92...).

7) La tecnología posee más limitaciones intrínsecas que la "ciencia pura". En tal sentido, el interés práctico, un cierto grado de inmediatismo, los problemas éticos y otros muchos factores han limitado el desarrollo de la investigación en psiquiatría y psico(pato)logía e incluso puede entenderse que grupos enteros de profesionales estén relativamente desinteresados por la investigación en estos campos: Nuevamente en estas situaciones habría que entender de entrada esa realidad como una de las sevicias propias del conocimiento técnico, al menos antes de proponer explicaciones más ideológicas o más "ad hominen".

8) En tanto cumplen esas condiciones y estructura, creo que hoy podríamos considerar que, en realidad, existen varios paradigmas o, tal vez con más propiedad, programas de investigación en "tecnología psiquiátrica" que han de ser considerados progresivos para el desarrollo de nuestra disciplina. Es el tema que quería tratar en los siguientes apartados.

5. Un esquema de algunos de los problemas epistemológicos principales de la psiquiatría contemporánea.

Seguimos encontrándonos hoy, por tanto, con la situación que, en otro momento, desde el punto de vista epistemológico, he llamado de "la 
psiquiatría en la encrucijada" (97-99). De hecho, en el fondo de todas los problemas epistemológicos o metateóricos encontraremos una serie de cuestiones comunes:

1. Las críticas externas a la psiquiatría: hace unos años, la crítica antipsiquiátrica. Hoy, las críticas sociales, sociológicas y sociopolíticas a nuestros métodos, sistemas, teorías, actitudes...

2. La crisis de las relaciones entre la psiquiatría y la psicología, relación en crisis donde las haya, matrimonio "obligado pero conflictivo" desde el día de la boda.

3. Reconsideración del paradigma dominante en la psiquiatría contemporánea. Por mucho que se diga que, como en el resto de la medicina, es el paradigma biopsicosocial, creo que hemos de ser sinceros y admitir que ello no es sino una vacua declaración de intenciones. Los paradigmas dominantes en nuestras disciplinas de la salud mental, como acabamos de recordar, han sido:

I. Una versión primitiva del biologismo a la que se ha llamado tradicionalmente organicismo. Y s u versión evolucionada actual: la perspectiva, más metafórica (o "sinecdótica") que real, de las neurociencias. ${ }^{4}$

II. El paradigma psicoanalítico o psicodinámico, un paradigma de base psicológica, al igual que su programa competidor.

III.El paradigma o programa de investigación conductual o conductista, en su versión radical, o en su versión suavizada, cognitivo-conductual o, más modernamente, cognitiva.
Los tres siguen teniendo una fuerte presencia en la psiquiatría y la psicopatología de nuestros días y no ha habido todavía una decantación de sus posibilidades. Lo que parece apuntar, más bien, son posibilidades de integración. Pero es que, en nuestra disciplina, como en todas las disciplinas psicoterapéuticas de nuestros días, otra serie de problemas de casi igual relevancia vienen a complicarnos la situación: si estamos hablando de controversias paradigmáticas dentro de la psicología y la psiquiatría, no debemos olvidar que, además, en una disciplina que hemos definido como interdisciplinaria con predominio biológico (la psiquiatría), aparecerán entonces otra serie de problemas teóricos y epistemológicos:

Primero que nada, las polémicas entre los paradigmas dominantes en las otras dos ciencias de base de la psiquiatría y la psicopatología aplicada: la biología y la sociología. A menudo, esa controversia entre paradigmas aparece subrepticiamente en las discusiones producidas por las diversas interrelaciones intercientíficas (e interparadigmáticas), de cuya influencia con frecuencia no somos conscientes, a pesar de que están determinando nuestra práctica cotidiana: por ejemplo, la metáfora de la administración de drogas como metáfora dominante en la terapéutica, está influyendo de forma decisiva los medios de validación y evaluación de todas las terapias en nuestros días, incluso aunque dichas terapias no sean farmacológicas $(40,41)$. Si a dichas polémicas y posiciones controvertidas les añadimos las propias de la psicología y la psico(pato)logía, a las cuales he aludido un poco más arriba, con 
sus tres paradigmas aún es disputa (biologista-neurocientífico, psicodinámico y cognitivo-conductual), tendremos entonces un panorama más completo de la situación de la epistemología de nuestra disciplina. Imaginemos siquiera un momento la complejidad de la problemática que podría plantearse si lográramos incluir asimismo las controversias interparadigmáticas dentro de la sociología, con sus paradigmas y actitudes ideológico-políticas en disputa $-y$ de forma tan activa y crucial en esas ciencias. Una repercusión claras de las mismas es la polémica, hoy desgraciadamente poco tenida en cuenta en nuestro ámbito, entre los factores de riesgo sociales como favorecedores de psicopatología o como precipitantes de "deriva social" $(43,45)$.

Pero es que, además, todas estas polémicas y controversias vienen complicadas por el hecho de que, a menudo, se utilizan epistemologías derivadas diferentes entre los diferentes paradigmas de la misma ciencia o disciplina $-\mathrm{y}$, desde luego, frecuentemente dentro del mismo paradigma. También porque, como ya hemos dicho, un elemento subliminal de cada paradigma pero, sobre todo, de cada comunidad científica, está formado por la normativa implícita y explícita de sus relaciones con el poder y, por lo tanto, por su posición en el modo de producción, distribución e intercambio social. Me refiero al poder económico que esa comunidad científica puede proporcionar al poder político $(y$, desde luego, a la propia la comunidad de científicos), poder ideológico de determinados paradigmas (por ejemplo, el que durante decenios tuvo el paradigma biologista del racismo en nuestra disciplina, que llegó a justificar la eliminación física sistemática por parte de psiquiatras alemanes universitarios de centenares de miles de pacientes mentales: tabla 5, 66). Pero, como antes recordé, también hay que incluir en este apartado los criterios implícitos de hasta qué extremo se puede utilizar el efecto Utah y el efecto Darsee para mantener posiciones, privilegios y prebendas $(12,16,19$, 119-124). Para muchos epistemólogos y para muchos investigadores de la psiquiatría este tipo de fenómenos no son propiamente epistemológicos. Desde una posición postkuhniana de la teoría de la ciencia, creo que, en buena medida, lo son, pero me costaría determinar en cuánta medida. De todas formas, su capacidad de penetración en lo que se define como científico en nuestra disciplina e incluso su penetración en la metodología científica y en sus resultados es tan intensa y profunda, que no nos queda más remedio que admitir esa realidad, a pesar de los riesgos de historicismo que encierra.

Intentando sistematizar ese conjunto de problemas epistemológicos refiriéndolo más en concreto a la Psiquiatría, podríamos esquematizar una problemática compleja con al menos los siguientes grupos o componentes:

a) Problemas epistemológicos de las ciencias biológicas y las ciencias humanas en general.

b) Problemas epistemológicos particulares de la Psicología, como ciencia básica en la Psiquiatría: los derivados de la elucidación de los fundamentos epistemológicos de la psicología como ciencia y del análisis de las representaciones que los psicólogos $(\mathrm{P})$ proponemos de los actos por los que el 
sujeto (S) aprehende el mundo de los objetos $(\mathrm{O})$.

c) Problemas derivados de la posición o estatuto epistemológico de la Psiquiatría en el conjunto de saberes técnico-científicos: Como ciencia, como técnica, como tecnología, como artesanado...

d) Problemas derivados de su posición en el abanico o clasificación de las ciencias y las técnicas contemporáneas: ¿Hemos de considerarla como una disciplina fundamentalmente psicológica o como una disciplina fundamentalmente biológica?.

e) Junto con una serie de problemas derivados del entrecruzamiento e interrelación, dentro de la Psiquiatría, de las disciplinas sociológicas, psicológicas y biológicas. Fundamentalmente, del reduccionismo o reduccionismos posibles de la psico(pato)logía y la psiquiatría: el reduccionismos biologista, el reduccionismo psicologista y el reduccionismo sociologista.

f) Así como los problemas derivados de las luchas interparadigmáticas de cada disciplina de base.

g) Problemas derivados del uso de epistemologías "derivadas" (Piaget 71,72) diferenciadas por parte de cada paradigma o dentro de cada paradigma: empirismo, positivismo, constructivismo...

h) Y los problemas e influencias ideológicos y políticos que incluye cada paradigma --y la comunidad científica y el trabajo tecnológico en particular. Muchos autores e investigadores psiquiátricos, e incluso epistemólogos profesionales defensores de posturas prekuhnianas, discutirían el que este último grupo de problemas pudiera considerarse problemas epistemológicos.

Mi hipótesis general es que en fondo de todos los problemas epistemológicos e incluso de los problemas teóricos de la psicopatología y la psiquiatría actuales subyace siempre una problemática (de epistemología interna) de alguno de esos siete (u ocho) tipos y que, consecuentemente, aparecerán problemas con el objeto de la psico(pato)logía y la psiquiatría e incluso a nivel de epistemologías derivadas: la aplicación dominante de alguna de las perspectivas antes nombradas supondrá y favorecerá nuevamente filosofías atomistas, fenomenológicas, empiristas, constructivistas... La segunda hipótesis general es que esos problemas se hayan frecuentemente obscurecidos y confundidos por influencias de poder, ideológicas y económicas tal vez intrínsecas en algunos de tales programas de investigación (influencias que conforman el apartado $h$ ), pero que son más amplias y determinantes que a nivel meramente epistemológico, desde luego.

Creo que en este campo, como en otros muchos de los saberes contemporáneos, no hay que dejarse deslumbrar por la abstracción y la especulación: a menudo, la tensión generada por esos conflictos y problemas está muy sobredeterminada ideológicamente por el poder universitario y el conglomerado sanitario-industrial. Como digo, no tengo del todo claro que, como Feyerabend (30-32) y un cierto Kuhn (1962) tal vez defenderían, estos 
problemas puedan considerarse "epistemológicos". Pero, en todo caso, aunque no sean temas centrales de esta comunicación, no quiero que la necesaria abstracción de ésta favorezca la idea "antipolítica", tan en boga últimamente, de que la base económica y lo que antes llamábamos la "superestructura" dominante no ejercen un poder importante, a menudo determinante, en las diversas posturas técnicas, teóricas e incluso epistemológicas de todas las disciplinas de una formación económico-social --y, por lo tanto, de la Psiquiatría.

Un ejemplo: En psicoanálisis de pacientes psicóticos y de pacientes con conflictos psicóticos estamos acostumbrados a encontrarnos con elementos que nos confirman nuestra perspectiva de la existencia de una psicodinamia del deterioro y la mejoría psicótica... Pero también, con la existencia de núcleos y defensas, como las simbiótico-adhesivas (121) muy difícilmente alterables, cambiables, mediante cualquier tipo de tratamiento (y que determinados tratamientos psicológicos o farmacológicos pueden incluso empeorar). Eso nos obliga a plantearnos una y otra vez la realidad de los determinantes biológicos y psicológicos del síndrome.

Pero si, como se afirma frecuentemente, la esquizofrenia fuera una "enfermedad genética" (aquí ya no se la llama trastorno, sino "enfermedad": se hipertrofia aún más el biologismo), si fuera una "enfermedad" genéticamente determinada, la concordancia entre gemelos monocigóticos sería de 1.0 ... cuando en realidad es del 0.31 entre ese tipo de gemelos en un estudio poblacional
$(49,82)$. Un buen argumento para el trabajo y la investigación paralela y convergente... de los determinantes sociales y psicosociales de la esquizofrenia. Máxime por cuanto los últimos estudios con gemelos arrojan cifras de concordancia menores aún $(27,4 \%$ para los gemelos monocigóticos y $4,8 \%$ para los dicigotos), inferiores incluso en los casos de esquizofrenia menos crónica $(20,82)$.

Una situación similar ocurre a menudo en la investigación acerca del autismo, un síndrome en el que, muy probablemente, los factores de riesgo connatales (y, probablemente, los genéticos) es posible que jueguen un importante papel. Pero de ahí a creer que la vía casi única de investigación del aumento espectacular de la incidencia del autismo en el Silicon Valley californiano, sea crear un banco genético (89), implica una ceguera biologista tan extrema, una falta de experiencia clínica y psicopatológica, una falta de atención a los temas familiares que resulta, como poco, ejemplar, es decir paradigmática... de los excesos del biologismo. Sobre todo si uno no olvida algunos datos psicosociales y psicodinámicos. Pero claro, éstos no forman parte del paradigma dominante (o de la ideología dominante): por ejemplo que, como recuerda Silberman (89), Silicon Valley está en gran parte habitado por seres de uno y otro género vitalmente presionados hacia el desarrollo del hardware y el software, o sea, al trabajo intelectual más abstracto, que viven a menudo en parejas con la misma profesión, que trabajan más de diez horas diarias por término medio ( ¿a qué hora ven a los hijos?), que están sujetos a todo tipo de presiones laborales... 
Todos los ejemplos anteriores y la actitud crítica que implican no debe tomarse como un menosprecio de la investigación biológica de este trastorno y de otros muchos. Los progresos en el conocimiento de las afecciones neuropsiquiátricas genéticamente determinadas han sido extraordinarios en los últimos años y están acelerándose día a día: es el caso de los determinantes hallazgos de la última década en el conocimiento de las enfermedades de Canavan, Tay-Sachs, Huntington, CharcotMarie-Tooth, de la distrofia miotónica, de la atrofia muscular espinobulbar, de la ataxia espinocerebelosa, del Alzheimer y, más recientemente, en algunas formas de Parkinson grave... Para algunos, entonces, la biología molecular y, más aún, el Proyecto del Genoma Humano proporcionarán la explicación, "la (verdadera) etiología de los trastornos mentales más graves". Para otros, incluso, de todos los trastornos mentales. Aunque otros muchos, algo más parsimoniosamente, pensamos que gracias a esos avances conoceremos mejor los elementos biológicos de la determinación de muchas afecciones neurológicas y de algunos trastornos mentales.

El problema más grave radica en el hecho de que, pese a la tosquedad de ciertos argumentos biologistas, el reduccionismo biologista no es un tema puramente estético, teórico y epistemológico: aprovechando esos razonamientos analógicos y la gran capacidad de influencia del efecto Utah (16, 122-123) de cualquier droga que prometa actuar sobre un neurotransmisor diferente, o mediante diferente mecanismo, se diseñan fármacos directamente apoyados en esas perspectivas analógicas y primitivas del funcionamiento de los neurotransmisores, drogas basadas en una"moderna" visión hidráulica del cerebro y de la psiquiatría consecuente: la psiquiatría que llamo de las micropipetas cerebrales. Pero, como decía no hace mucho $(122,123)$, el problema es que esos fármacos compiten entre sí en el sacrosanto mercado (de la salud, en este caso). Compiten en nuestras poblaciones, en nuestras salas de espera, en nuestras consultas y en nuestros pacientes con una intensidad creciente, a menudo belicosa... Ahora bien: en toda guerra hay muertos. Y en los "campos de batalla", los muertos son reales. Algo bien obvio que demasiado a menudo parece olvidarse: ¿Cómo entender si no que en 1998 un determinado psicofármaco que aquí prefiero no especificar, pudiera ser retirado del mercado al año de haber sido introducido tras mostrarse involucrado en varias muertes por problemas cardíacos? ¿Qué pasó con los estudios farmacocinéticos y experimentales previos? ¿Y con los estudios clínicos pre-lanzamiento? ¿Y con los numerosos estudios clínicos post-lanzamiento? ¿Y con el riesgo en el que se ha colocado a los mil cuatrocientos pacientes que recibieron ese mismo tratamiento ${ }^{4}$ ? ¿Qué pasó con los estudios clínicos aleatorizados controlados? ¿Es que son un método falaz? ¿Es que los investigadores falsearon la datos? ¿Es que también los estudios aleatorizados controlados (EAC) y los meta-análisis consecutivos son susceptibles de caer bajos los "sesgos del investigador" hasta el extremo de haber infravalorado tan gravemente los efectos secundarios indeseables del fármaco?... ¿Y qué pasa con las responsabilidades éticas y 
científicas, por no referirme aquí a las legales, de los investigadores que firmaban esos estudios? $(12,16,19,119-120$, 122-123).

En el mismo sentido, habríamos de revisar centenares o miles de estudios sobre terapias psicológicas y psicosociales, en especial breves, que prometen tremendos e importantes resultados y que han mostrado la realidad de los mismos en estudios metodológicamente más que correctos $-\mathrm{y}$, por supuesto, aleatorizados controlados $(41,124)$. Y, sin embargo, esas técnicas y sistemas de trabajo luego resulta que no se extienden o no son accesibles a nivel clínico. ¿Qué está pasando ahí, en esta situación más que corriente?. Creo que a menudo puede rastrearse en esas situaciones la influencia de al menos cuatro fenómenos: Antes que nada, el efecto crisálida (las nuevas terapias a menudo tienen resultados mucho mejores... cuando comienzan a utilizarse: su eficacia y eficiencia disminuyen con el tiempo, con la extensión y generalización de tales terapias, con nuevos estudios que no repiten esos resultados...). En segundo lugar, a menudo el "efecto crisálida" tiene que ver con la deformación técnica estrecha de nuestra disciplina: se busca sobre todo la eficacia, pero sin atender para nada a los otros elementos que deciden la calidad de una terapia cualquiera (eficiencia, efectividad, oportunidad, seguridad, accesibilidad, etc: tabla 1). En tercer lugar, el error epistemológico interno de utilizar modelos teóricos y técnicos sesgados, tales como los modelos basados en la metáfora de la administración de drogas y los modelos médicos categoriales en disciplinas, situaciones y técnicas que no deberían dejarse dominar por tales metáforas. En cuarto lugar, el puro y duro efecto Utah: si se logra un impacto mediático adecuado en la comunidad científica y en los políticos que administran las subvenciones, basta con propalar excelentes resultados iniciales; cuando se compruebe su falsedad pueden haber pasado años o incluso decenios (16,122-123).

Podríamos poner otros muchos ejemplos de la sobredeterminación ideológica de nuestras disciplinas y cómo la misma interactúa con un elemento epistemológico fundamental de la misma en nuestros días: el reduccionismo biologista. Recientemente me he aplicado a ejemplificar la primera de las influencias (119-124). Permítanme reverdecer aquí algunos recordatorios y muestras:

Por ejemplo, del imperialismo del modelo médico biologista (y en una acepción reducida del mismo: el que se basa en la metáfora de la droga como paradigma (40-41,122-123)) resulta para mí "paradigmática" la tendencia reciente a la creación de "trastornos" o "enfermedades" diseñadas para fármacos concretos. Se sigue aquí un principio básico en mercadotecnia moderna: se puede vender para necesidades, pero es mejor crear las necesidades para vender. Las fobia social, el trastorno por déficit de atención con hiperactividad (rápidamente reducido, además, al problema de los niños hiperactivos), la cronificación de los duelos mediante el uso abusivo de psicofármacos en ellos, la yatrogenia masiva realizada con el uso masivo, inespecífico y crónico de antidepresivos en depresiones reales y supuestas... Claro que todo "queda en casa" porque, una vez que las depresiones no se solucionan "echando 
píldoras en las sinapsis" se puede postular que la depresión es una enfermedad crónica , recidivante y degenerativa...

A otro nivel, la metáfora de la droga puede observarse en el seguidismo de la práctica y la investigación en psicoterapia con respecto a ese "paradigma": así, se van creando (e investigando) psicoterapias para los diversos trastornos delimitados... por $\mathrm{y}$ para esa metáfora. Igualmente, asistimos a una enconada carrera por lograr psicoterapias cada vez más "orientadas al síntoma”, cada vez más breves y cada vez más investigadas con criterios... propios de la psiquiatría biologista. No es de extrañar pues que sólo algunas den los resultados apetecidos. El ideal asintótico a conseguir parece ser una especie de psicoterapia homeopática la cual, ofrecida en microgránulos, pueda ayudar a que los pacientes... ¿aguanten más años la medicación? Si bien yo mismo practico, he propuesto e incluso he investigado empíricamente sobre las terapias "de flash" o ultrabreves (108-109), he de recodar aquí que el otro término con el que las designé, que ha hecho menos fortuna (probablemente por determinantes también ideológicos), era el de "procesos de sensibilización a lo psicológico”, sistemas orientados a potenciar las capacidades personales de elaboración psicológica más que a tratar heterónomamente a los pacientes (108-109, 114-118). A pesar de esa plétora de psicoterapias supuestamente "eficaces y eficientes" que nos proponen la "solución" de trastornos de personalidad (¡incluso límites y narcisistas!) en más o menos cuarenta sesiones psicodinámicas o cognitivas; a pesar del "supermercado bibliofílico" en el cual venden a los médicos en general y a los generalistas en particular que lo único que necesitan en cuanto a recursos psicoterapéuticos son las ultraeficaces terapias cognitivas $(41,42)$, creo que ya es hora de que, desde cualquier paradigma de la psicoterapia, levantemos la voz y digamos, cuando hay que decirlo, que no es para tanto, que hay mucho efecto Utah y efecto Darsee en esos estudios -por muy EAC que sean--, que el rey va desnudo...

Si no lo hacemos pronto y fuerte, están al caernos (encima) nuevos y maravillosos sistemas de cuidados tales como el managed care y similares... Poco importa que en su país y economía de origen (los USA) no hayan demostrado aún su utilidad, lo que sólo podrá demostrarse a medio o largo plazo (un mínimo de cinco años, como en todo tema de salud mental). Poco importa que su versión reformada, los Assertive Community Treatments tampoco hayan demostrado si son sostenibles (efectivos) al cabo de los años y que sus efectos iniciales no son puramente efecto crisálida (60). Ciertamente, se trata tan sólo de sistemas para modelos de gestión sanitaria bastante despreocupados de temas tales como la equidad, la solidaridad, la universalidad... Pero es que, además, suelen engarzar estrechamente con sistemas de "cuidados" tales como el case management. Desde luego, a los sistemas sanitarios en los cuales tratan de implantarse -y a los que siguen su modelo-- les cuesta lograr que clínicos a los que se ha desprogramado y desmotivado para la atención globalizadora y el cuidado de los pacientes según el sistema de "clínico referente" --apoyado adecuadamente por grupos de 
reflexión y/o supervisión--. Por ello, se inventa el sistema del CM, MC o los ACT: a cada paciente se le asigna un "case manager" (un manageador) que determina las necesidades personales, desarrolla un plan de cuidados, procura que sean proporcionados esos cuidados, monitoriza la calidad de los mismos y mantiene el contacto con el paciente. Es decir, que realiza el trabajo del "clínico referente" que nosotros proponíamos desde 1981 y $1992 \ldots$ pero, al parecer, sin clínica: los clínicos (psiquiatras, psicólogos, trabajadores sociales, enfermeros...) se convierten así en "operarios de una cadena productiva de cuidados parcializados" coordinados por un encargado, el "case manager", en la afortunada metáfora de Eisenberg (1995,20). Los resultados de meta-análisis independientes sobre tales "sistemas de cuidados" insisten en las dudas con respecto al presente y al futuro de los mismos (Marshall et al 1998, 60), pero hoy por hoy muchos de nuestros gestores y planificadores parecen tan "pasmados" por lo norteamericano que están empeñados en introducirlos entre nosotros. Algunos somos sumamente escépticos en ese tema: tal vez va a resultar difìcil sustituir con medidas tecnoburocráticas la falta de motivación, de formación y de apoyo a los diferentes tipos de clínicos que podrían ejercer esa labor globalizadora de los cuidados del paciente Cómo lograrlo, si, por ejemplo, en una reciente encuesta personal que realicé a los MIR de Psiquiatría y PIR de toda Catalunya en febrero del 2002, durante su postgrado habían realizado ¡entre 0 y 1 horas de formación en entrevista clínica! Durante la carrera, según su propia declaración, sus horas lectivas en técnicas y prácticas de entrevista habían oscilado ¡entre 0 y 4 ! En el mismo sentido, cada vez hay menos interés y más resistencia en esos mismos profesionales (e incluso, aunque suelen ser más favorables, también entre los médicos de familia), ante la posibilidad de realizar prácticas de observación sin intervención, tales como solemos proponer a los discentes $(1,88,122)$ : observación de salas de espera, de consultas, a domicilio, de consultas de médicos de familia o pediatras... Necesitaremos muchos "manageadores de casos" para evitar que profesionales tan concienzudamente de-formados puedan no disociar al paciente en partes o piezas, según la metáfora de la cadena de reparación y montaje de Eisenberg (20). A todos los niveles (clínicos, teóricos, de gestión, epistemológicos...) se sabe que las dificultades para la entrevista y para un enfoque globalizador se hallan en la base de tales problemas y que sus consecuencias son hoy sumamente graves no sólo en psiquiatría, sino en el conjunto de la medicina $(12,19,25-27,61,62,104)$ : hasta el extremo de que estudios recientes realizados en nuestro país afirman que al menos el 12 por ciento de los ingresos hospitalarios tiene por causa... los fármacos (12). Y, cuando se leen los motivos de tal mal uso farmacológico lo que queda más claro es que la combinación entre 1), la creencia "epistemológica" en la omnipotencia biologista unida a 2), la falta de una perspectiva teórica integral del paciente junto con 3), problemas técnicos en las entrevistas, explican gran parte de ese disparate asistencial, causante de una parte no despreciable del gasto sanitario global $(12,61)$. 
La muestra máxima de 10 deletérea que puede resultar la mezcla entre el reduccionismo ( $\mathrm{psicologista,}$ sociologista, biologista) y la ideología de la dominación y el control es la que llevó a la psiquiatría de la era nazi (Müller-Hill 1991, 2002: 66). Ya es hora que los propios psiquiatras hablemos de ello en vez de seguir ocultando con un silencio (¿temeroso?) que colegas nuestros participaron de forma destacada en las malpraxis, asesinatos y genocidios cuyo resumen ilustro en la tabla 5. Y que buena parte de los psiquiatras alemanes lo sabían... y callaron. Mas no se crea que escojo ese ejemplo porque ataca de forma directa la ideología geneticista y de forma indirecta el biologismo. No: lo hago porque es un caso extremo, paradigmático, y demasiado culposamente silenciado. Ahora bien: de los resultados de esa espirituosa mezcla entre reduccionismo epistémico e ideología manipuladora pueden verse ejemplos psicologistas y sociologistas. Por ejemplo, hoy en día ya hemos de ser más sinceros y admitir que la desinstitucionalización de los manicomios, impulsada y realizada a menudo mediante posturas eminentemente ideológicas ha podido llevar también a menudo a "arrojar a pacientes graves en la comunidad" sin haber creado previamente las suficientes estructuras de acogida, de tratamiento e intermedias. Con el resultado de un aumento desmedido de los sufrimientos de los pacientes y sus familias, que suficientes sufrimientos tienen ya. Pero, desde luego, nada tan ilustrativo del poder infiltrador de la ideología de la manipulación y la insolidaridad como los horrores resumidos en la tabla 5. Una muestra, además, de cómo la ideología antisolidaria, apoyada en deformaciones reduccionistas, puede resultar deletérea no sólo para una técnica o tecnología, sino para centenares de miles de seres humanos. Los datos que resumo en la tabla 6 , recogidos de un estudio reciente de Farber et al (2001: 27), pueden tomarse como otra muestra fehaciente de cómo la deformación ideológica puede socavar... incluso los fundamentos de un técnica y una tecnología y hacer que se olviden o disocien componentes cruciales de la misma.

Permítanme pues resumir una consecuencia general de todo lo anterior, una consecuencia que, en nuestro caso, proviene de una breve incursión por la epistemología interna de nuestras disciplinas, pero que resulta similar en otras disciplinas. Y la consecuencia es que resulta evidente que, en nuestra perspectiva de lo que es la racionalidad epistémica (científica o tecnológica), hemos de tener mucho más en cuenta las aportaciones kuhnianas y postkuhnianas sobre la historia, sociología y psicología de la ciencia y las comunidades científicas y cómo esos elementos influencian intrínsecamente en lo que llamamos ciencia y tecnología. Ello ha de significar, consecuentemente, proponer unas orientaciones para la psiquiatría y las disciplinas de la salud mental alternativas:

1) Más basadas en lo relacional, en la relación o interacción humana.

2) Por tanto, integrando teórica y técnicamente las emociones y lo inconsciente.

3) Basadas en la solidaridad y en su estudio y desarrollo, más que en la disociación y en el modelo técnico (de gestión) y epistemológico del mercado, 
4) Con la confianza de que podrían resultar hoy tan o más eficaces, eficientes y, por supuesto, efectivas que las propuestas basadas en la disociación asistencial, la colusión en el anonimato, el reduccionismo biologista, la veneración al dios mercado y el librecambismo .

5) Lo cual implica una forma diferente, por supuesto, de afrontar y aceptar la globalización. Pero hemos de dejar por ahora aquí esas otras consecuencias de la crítica epistemológica de la situación de nuestras disciplinas.

\section{Cuatro (antes cinco) epistemologías} derivadas o teorías filosóficas

Partimos y hemos de partir pues de la realidad de que en las ciencias humanas y ciencias sociales, las dificultades epistemológicas fundamentales no suelen provenir, en último término, ni del objeto tratado ni del método. El gran obstáculo, ligado a la dificultad de descentración individual, consiste en que el hombre de ciencia --y mucho más incontroladamente, el técnico o el artesano--, como todo hombre, mantiene unas actitudes ideológicas y filosóficas (y éstas incluyen siempre una toma de postura en el diagrama epistemológico y gnoseológico $S<-->O$, sujeto $f>$ objeto, $\mathrm{y}$, por tanto, una serie de nociones sobre el papel de la práctica en el conocimiento).

Como han señalado numerosos autores (51-54, 57, 71-74) esta dificultad aumenta según avanzamos en las ciencias en dirección a las ciencias psicológicas y socioculturales, por su mayor relación con las ideologías y las prácticas sociales (87).
Este es ya el terreno de las epistemologías derivadas (nivel $D$ de Piaget: 71-72), en el que me importa ahora resaltar cuatro filosofías básicas a más de cuatro "sistemas" o "programas de investigación" de la psicología y la psiquiatría: me refiero a las perspectivas filosóficas del empirismo y positivismo, la fenomenología y la filosofía existencial en sus nuevas formas y "deshabillés", las perspectivas "hermenéuticas" y las perspectivas constructivistas. De esta enumeración pueden ustedes observar la ausencia de una perspectiva filosófica y epistemológica que sí citaba en mis trabajos de las décadas de los años setenta y ochenta: me refiero a las corrientes filosóficas y epistemológicas del "materialismo dialéctico". Y no las excluyo de mi enumeración por ese deseo tan generalizado de "renegar del pasado" que impregna nuevamente nuestra vida cultural. Mucho menos aún, por ningún oscuro "ajuste de cuentas" con un pasado aún no pasado y del cual no creo que debamos avergonzarnos en la medida en que nos opusimos a él. Las excluyo de la enumeración de las epistemologías más influyentes en al actualidad porque, querámoslo o no, han dejado de ser actualidad. La caída del muro de Berlín--y la caída de países enteros, con la miseria y el sufrimiento de millones de personas que, al menos por el momento, ha aparejado-en el ámbito acerca del cual estamos reflexionando no hizo sino confirmar el "rigor mortis" de unas perspectivas estalinistas --más que leninistas-- y leninistas --más que marxianas-- de la filosofía y la epistemología "dialéctica" (aunque que, por otro lado, Marx y 
bastantes autores "marxianos" o "marxistas" han pasado a ocupar su puesto en la historia de las ideas, de la cultura y de la humanidad en general).

De esas corrientes filosóficas derivadas del materialismo dialéctico esclerotizado poco hay que decir en este momento. Eliminadas casi de raíz las posibilidades de colaboración con el psicoanálisis (y no queremos entrar aquí de nuevo en la serie de lugar comunes en que han solido consistir los análisis del freudomarxismo, salvo excepciones), tales orientaciones filosóficas se centraron mucho más en la sociología, la economía $\mathrm{y}$ en todas las disciplinas en las que la dimensión histórica tiene una relevancia especial. Su desviación progresiva hacia el empirismo más radical ha sido muy notable. El punto de partida fundamental de la desviación empirista de la epistemología materialista dialéctica podríamos rastrearlo a partir de la "teoría del reflejo" que sirve en buen aparte de base a la gnoseología leninista (Lenin, 1948). Con la primacía de $O$ y el enfoque mecánico de las relaciones $S \times O$ (simplificadas a menudo en $S<--O$ ) se abrían de par en par las puertas a la dogmatización y a-dialectización del programa epistemológico de las ciencias sociales en los países socialburocráticos.

Teniendo en cuenta esa exclusión ¿cuáles son las perspectivas filosóficas en general y epistemológicas en particular que están sustentando la epistemología de la psico(pato)logía y la psiquiatría contemporáneas? Veremos que cada una de ellas ha de incluir como elemento fundamental una toma de postura en el diagrama $\mathrm{S}<-->\mathrm{O}$.
6.1. El empirismo y el positivismo.

En estas páginas vamos a entender por empirismo "la doctrina filosófica y en particular gnoseológica según la cual el conocimiento se halla fundado en la experiencia" (Ferrater 1978:29). El empirismo suele contraponerse al racionalismo (el conocimiento se funda en la razón, en el pensamiento) y al innatismo (el conocimiento, al menos en sus aspectos o componentes fundamentales, es innato). Para los empiristas, el sujeto cognoscente es como una "tabula rasa" en la que se inscriben las aferencias procedentes del "mundo externo". Ferrater (29) propone agrupar los tipos de empirismo en tres: "el psicológico, el gnoseológico y el metafísico. Para el primero, el conocimiento se origina íntegramente en la experiencia; el segundo sostiene que la validez de todo conocimiento radica en la experiencia; el último afirma que la realidad misma es empírica, es decir, que no hay más realidad que la que es accesible a la experiencia y en particular a la experiencia sensible".

En cuanto al positivismo, vamos a entenderlo aquí en un sentido derivado del original, propuesto por A. Comte --quien, no hay que olvidarlo, defendió no sólo una teoría de la ciencia, sino también y muy especialmente, una perspectiva renovada de la sociedad y la religión. Como teoría del conocimiento, el positivismo se niega a admitir otras fuentes que no sean los hechos y a investigar otra cosa que no sean las relaciones entre los hechos "positivos". Subraya el cómo y tiende a marginar o posponer la respuesta al qué, el por qué y el para qué. El positivismo rechazará cualquier 
metafísica, cualquier conocimiento $a$ priori, cualquier posibilidad de intuición directa de lo inteligible... Pretende atenerse a lo dado y no salirse jamás de "lo dado". De ahí su hostilidad a la construcción y a la deducción, a la sistematización, a la axiomatización... Sin embargo, el positivismo lógico del siglo XX, difundido por el Círculo de Viena, tendía a unir la sumisión a lo puramente empírico con los recursos a la lógica formal, al tiempo que difundió la idea metacientífica de la verificación como necesidad epistemológica del conocimiento científico (8-11, 42, 63-65, 85).

El empirismo mantiene una activa supervivencia en las ideologías y escuelas psicológicas, psiquiátricas y psicoterapéuticas de los países industrializados. Sin duda el empirismo y el neopositivismo lógico han sido uno de los orígenes y fuerzas motrices fundamentales de la psicología (y la sociología) científica y en ese sentido permanecen como matriz epistemológica fundamental de las dos corrientes psicológicas y psiquiátricas importantes hoy en los países "postindustriales": la psicología y la psiquiatría "biologista" y las diversas formas de conductismo. Pero, en tanto que filosofía y en tanto que ideología, el empirismo ha desempeñado en psicología y psiquiatría un papel de encauzamiento que ha sido rechazado, por restrictivo, por otros muchos profesionales, a pesar de que el empirismo inglés (Bacon, Hobbes, Locke...) ha tenido importantes repercusiones sobre la psicología y, en especial, sobre la teoría de las técnicas de psicoterapia (85).

En tanto que epistemología, el empirismo, en su intento de primar el elemento $\mathrm{O}$ y su observación y sistematización en el diagrama $S<-->O$, no se contenta sólo con exigir condiciones experimentales en todas las disciplinas que estudian datos factuales, sino que intenta reducir la experiencia a menudo a un simple registro de datos observables en lugar de ver en ella, como otras epistemologías, una estructuración activa de los objetos, dependiente siempre de las acciones del sujeto y de sus intentos de interpretación (71-72, 98, 104-124). Así se explica, por ejemplo, que varias teorías del aprendizaje y de la modificación de conducta consideren los conocimientos adquiridos como una especie de copia de la realidad y hagan hincapié en los "refuerzos" externos que consolidan dichas asociaciones, o que determinadas calificaciones clasificatorias de conductas, a menudo parcializadas, sean tomadas por "entidades morbosas" o incluso por "enfermedades": la moda del diagnóstico dual es una buena expresión de tal tendencia. Por el contrario, las teorías no empiristas en este aspecto insisten en los factores de organización y en los refuerzos internos (cognitivos o emotivos, según la técnica de psicoterapia concreta). Sin embargo, no hay que olvidar que la insistencia del empirismo en la metodología, la contrastación, la experimentación, ha servido de llamada de atención a otras escuelas y orientaciones epistemológicas e indudablemente tal llamada ha producido importantes frutos de cientificidad.

Mi opinión particular es que en la psiquiatría actual sigue predominado la filosofía y "epistemología derivada" empirista y positivista. Pero, como mantenía ya en $1983(98,101)$, en cualquier 
aproximación psicosocial, el empirismo favorece el reduccionismo y, por lo tanto, una visión parcial y deformada de la realidad a transformar: la conducta, estructura de personalidad, conflicto o "sistema familiar" a estudiar o tratar (85). El problema sobreañadido es que, probablemente, esa visión "parcial y deformada" nos impedirá captar con suficiente profundidad la complejidad de la realidad humana y social. De esa forma, las alternativas y prácticas propuestas no resolverán las principales contradicciones enfrentadas ni abrirán los caminos para hacerlo, tal como han resaltado con evidente originalidad e ingenio alguno de los autores sistémicos en su crítica de algunos de los modelos conductistas radicales (por ejemplo, el skinneriano).

De hecho, numerosos autores de orientación conductual o derivadas muestran hoy en día una aceptación creciente por modelos psicológicos que admitan procesos mediacionales entre la situación estimular y la respuesta del organismo humano. Como poco, en el caso de que esos procesos no directamente observables permitan "out-puts" operativizables y susceptibles de ser procesados por un análisis experimental de la conducta sujeto a menos prejuicios empiristas (es decir, propios de la epistemología empirista).

En la moderna psiquiatría académica podemos estarnos encontrando pues con un auténtico despropósito histórico: mientras que las ciencias de base de la misma (medicina, biología humana e incluso psicología) se desplazan en su perspectiva epistemológica hacia otras epistemologías de base, la psiquiatría está acantonándose nuevamente en el empirismo. Y en un empirismo complejamente entremezclado con consecuencias de la perspectiva fenomenológica (por ejemplo, en la tan traída y llevada diferenciación entre psicopatología "endógena" y "exógena" o entre "comprensión" y "explicación") y con dosis abrumadoras de reduccionismo biologista u organicismo.

\subsection{La fenomenología y la filosofía} existencial.

Como filosofía, la fenomenología no pretendía realizar una investigación científica ni marcar los métodos de las ciencias, sino presentar una alternativa a esas ciencias en un conocimiento más "auténtico" de las realidades consideradas, partiendo para ello de la primacía de la experiencia y vivencias del sujeto (S) en el acto de conocimiento. Pero una filosofía paracientífica como es la fenomenología, corre siempre el riesgo de depender del estado concreto de las ciencias que trata de criticar. Así, Husserl atacó fundamentalmente la psicología empirista $\mathrm{y}$ asociacionista de principios del siglo $\mathrm{XX}$, para poder construir al otro lado una forma de conocimiento "más auténtica". El resultado está a la vista: la psicología y sus técnicas terapéuticas han seguido evolucionando y, de la mano del conductismo, la psicología experimental, la psicología dinámica y la psicología genética, han roto todas las fronteras, de forma que hoy habría que plantear el problema en términos muy diferentes (muchos de ellos ya susceptibles de verificación).

Para Husserl, el método fenomenológico permite captar la experiencia tal y como la conocemos 
subjetivamente dentro de la experiencia fenoménica y no desde fuera, como pretende hacerlo la ciencia. El método fenomenológico está compuesto por tres fases: la descripción fenomenológica, la reducción fenomenológica y la intuición eidética. Esa intuición de la esencia o eidética en nuestro campo significaría la captación del significado y destino esencial de los fenómenos psíquicos.

No es difícil encontrar reminiscencias idealistas en las teorías fenomenológicas y existencialistas, en especial en aquéllas como la de Binswanger, en las que se propone que las estructuras ontológicas a priori (diseños del mundo) crean o hacen literalmente posible la experiencia... Recientemente, esas estructuras se buscan con ahínco en la bioquímica cerebral, en los neurotransmisores o en las membranas y estructuras sinápticas.

Sin embargo, como puede observarse con sólo tener mínimamente en cuenta la anterior descripción elemental de la fenomenología, cuando muchos autores, clínicos e investigadores en psiquiatría hablan de psiquiatría fenomenológica están cometiendo un error de bulto muy a la moda norteamericana y del DSM: tal vez quieran decir psiquiatría descriptiva porque, como acabamos de ver, la fenomenología como método de conocimiento está quedando cada vez más excluida del campo de la epistemología o teoría de la ciencia. Pero ¿una aproximación "descriptiva" sin tener en cuenta la metodología observacional, hoy ampliamente desarrollada $(1,88,117)$ ? Es difícil hoy sostener que el método fenomenológico proporcione por sí mismo conocimientos científicos o tecnológicos. Aunque tal vez el término "fenome- nológico" se use a menudo con otro sentido: para evitar pronunciar el contrasentido terminológico que supone la psiquiatría “ateorética”... O tal vez, incluso, para no explicitar otra realidad frecuente: psiquiatría (o psicología) antipsicoanalítica.

6.3. La perspectiva "hermenéutica" de la psicopatología, la psiquiatría y las técnicas de psicoterapia.

El planteamiento hermenéutico de la psicopatología y la psiquiatría se halla vinculado con la filosofía y con ciertos conocimientos humanísticos o culturales: historia, literatura, arqueología... Estos se distinguen por tener que tratar con fenómenos de gran complejidad y sin la posibilidad de utilizar los métodos experimentales. La metodología hermenéutica se basará, alternativamente, en la exégesis (exposición e interpretación) de textos y en la comprensión global del sentido, en buena medida "intuitiva" o "gestáltica". Vuelve a alejarse por tanto del planteamiento de las ciencias físicas, aunque ha acabado por incorporar algunos de los avances más susceptibles de integración de éstas.

La hermenéutica, que originalmente se aplicó a la interpretación de los textos bíblicos, recibió un gran impulso con la obra de W. Dilthey (1833-1911). Para Dilthey, la esencia del espíritu, de "lo psíquico", excluye la causalidad y, por lo tanto, la explicación y el atomismo, características todas ellas de las ciencias de la naturaleza. La vida psíquica debe ser comprendida intuitivamente y no a través del proceso de "explicación”. La comprensión intuitiva se refiere a una totalidad y no a fracciones o partes. De esta 
forma, Dilthey considera que la vida psíquica no se rige y estudia mediante causas y explicaciones, sino que sólo puede ser observada, descrita y "comprendida".

La influencia de una perspectiva hermenéutica es diferente en las diversas orientaciones de la psicopatología, la psiquiatría y las "técnicas de psicoterapia" existentes. Para Frank (1990), la investigación y transformación de los significados personales se hace explícita en las terapias humanístico-existenciales y en el psicoanálisis. Sin embargo, las terapias que sólo buscan cambiar la conducta del paciente ven la transformación del significado personal como una consecuencia del cambio de conducta, en vez de a la inversa.

Un punto esencial en la teoría psicoanalítica es que la historia vital que el paciente explica al terapeuta no puede tomarse como un relato objetivo, sino que se halla profundamente mediatizada por la vivencia que el paciente hace de su propia historia. Ello puede reintroducir al psicoanálisis y la psiquiatría influenciada por él (la "Psiquiatría Dinámica") en los dominios de la hermenéutica. En ese sentido, desde la perspectiva de las técnicas psicoanalíticas y fenomenológicas, el proceso de la interpretación se efectúa tras ordenar previamente el material expresado por el paciente y distribuirlo sistemáticamente por temas: sueños, síntomas y fantasías. Además, el material ha de pasar por el tamiz de la experiencia de la relación terapeuta-paciente y de la teoría psicoanalítica, que se ha elaborado a partir de un saber fundamentado en otras experiencias y teorías $(91-93,106,111)$.

Por otra parte, como he recordado recientemente (111), la idea de que el psicoanálisis no es una ciencia "natural" sino una "ciencia hermenéutica" proviene de diversos autores, tanto psicoanalistas como filósofos. Sin embargo, en realidad se trata de una idea directamente contraria a las apreciaciones del propio Freud y, desde luego, coincidente con muchos de los críticos del psicoanálisis, para los cuales éste es cualquier cosa antes que una "ciencia natural" (cfr. diversas perspectivas sobre el tema en 103 , 106,107, 111...).

En mi opinión, desde el punto de vista histórico- cultural, una serie de psicoanalistas, ante el empuje crítico de la orientación positivista de la ciencia, en vez de buscar nuevas argumentaciones, métodos de contrastación y comunicación en psicoanálisis, prefirieron optar por una "tercera vía": el psicoanálisis no sería así ni una "ciencia" (Freud) ni una "pseudociencia" (Bunge 10), sino una "ciencia especial", la mayoría de las veces emparentada con la hermenéutica. Una nueva versión de la delicada $\mathrm{Bambi}$ (122-123), pero esta vez en el terreno de la epistemología del psicoanálisis. En último término, para estos autores, la metapsicología o teoría psicológica de Freud no es sino un "cuerpo extraño" en el conjunto del corpus psicoanalítico: admitirán la validez de la teoría clínicopsicológica de Freud, pero realizarán una especie de "teorectomía" con los intentos de explicación científica del mismo, ciertamente influenciados por la ciencia coetánea y, por lo tanto, en buena parte empiristas y positivistas. Entre otras razones porque Freud admitía, como lo hacen los hermenéuticos en sentido contrario, que las proposiciones pueden dividirse en dos categorías irreconciliables 
entre sí: las verificables y las no-verificables con los métodos de la ciencia (entendida ésta, además, en el sentido de la físico-química y la biología ochocentista y de principios del siglo XX).

Sin embargo, en diversas formas y perspectivas, --y posiblemente por lo que tiene de válido el estudio del par significante - significado en los fenómenos socioculturales-- la hermenéutica y, a otro nivel, la semiótica, se han introducido asimismo en otras perspectivas de la psiquiatría, no sólo en la perspectiva dinámica: por ejemplo, en las perspectivas cognitivas y cognitivo-conductuales.

Beck y colaboradores $(3,4,85)$ señalan que los supuestos básicos forman la matriz de los significados y valores personales, el marco en el cual los acontecimientos adquieren relevancia, importancia y significado. Añaden, además, una clara referencia a una actividad hermenéutica, al afirmar que los supuestos desadaptativos difieren de los adaptativos en que los primeros son inadecuados, rígidos y exagerados. Por otra parte, a pesar de que el terapeuta puede valerse de distintos argumentos y ejercicios para ayudar al paciente a examinar la validez de sus creencias disfuncionales, la modificación de éstas no se produce por la cantidad de contraargumentos, sino porque alguno de ellos tenga un significado particular para la persona. De esta forma, la mejor evidencia contra los supuestos desadaptativos es la que el paciente genera por sí mismo o en colaboración con el terapeuta. Por lo tanto, también en el contexto de la concepción cognitiva lo hermenéutico es importante: el propósito de las técnicas cognitivas es el de proporcionar posibilidades de cambio en la organización cognitiva del paciente. Así, la hermenéutica se instala en el intento del terapeuta de entender la interpretación que el paciente hace de la realidad y de posibilitarle la consecución de un "significado nuevo" para de sus experiencias, más concordante con la realidad $(3,4)$.

Como he tratado más extensamente este tema del valor epistemológico de la hermenéutica en nuestras disciplinas (106,111), me limitaré a resumir muy esquemáticamente aquí mi postura: en esencia, no creo que la hermenéutica pueda considerarse hoy una verdadera epistemología, en el sentido de uno de los programas filosóficos que guían la ciencia y la tecnología (epistemologías internas). Puede ser una técnica y un método de comprensión, pero siempre de una jerarquía epistemológica muy inferior a los métodos científicos más comunes: estadístico-correlacional, experimental y observacional sistemático. En consecuencia, no creo que pueda defenderse como disciplina científica o como tecnología una práctica que esté basada fundamentalmente en la hermenéutica sin el concurso y la concurrencia de los demás métodos de la captación científica de la realidad.

6.4. La epistemología constructivista, del "realismo crítico", del "realismo interno" y del "realismo no representativo".

"Somos a la vez espectadores y actores en el gran drama de la existencia" (Niels Bohr).

Atenderemos ahora brevemente a la serie de corrientes epistemológicas que han intentado recientemente poner de relieve la importancia de la práctica en el conocimiento y el papel irrenunciable de 
la dialéctica $S<-->O$ en el programa epistemológico y gnoseológico: la experiencia no será ni un simple registro de datos "reflejados" en la conciencia ni el fruto de la sensibilidad, constructos, representaciones mentales o a-prioris (?) subjetivos e intransferibles del sujeto, sino una estructuración activa de los objetos que está en función de las acciones del sujeto, las respuestas del objeto y los intentos de interpretación y contrastación de hipótesis del sujeto. También llamamos "constructivistas" a estas corrientes porque no renuncian ni a los aspectos históricos, genéticos, diacrónicos del objeto, ni a los aspectos sincrónicos vistos como totalidad, como estructura. En ese sentido, las corrientes psicológicas y psicoterapeúticas basadas en esta epistemología deberán tener en cuenta en sus estudios tanto los aspectos genéticos como los estructurales, bipolaridad a la que renuncia por ejemplo el atomismo asociacionista, el conductismo clásico, la reflexología tradicional...

Pero, en un paso posterior, en mi trabajo de epistemología de 1978 (98) llamaba "constructivistas dialécticas", o simplemente dialécticas, a estas corrientes epistemológicas porque en su modelo gnoseológico, la relación $S<-->O$ es básica para el conocimiento, como en psiquiatría y psicoterapia han puesto de relieve diversas orientaciones de la psicología dinámica, las perspectivas cognitivas, algunas orientaciones modernas de la psicología del aprendizaje, las perspectivas sanitarias "centradas en el consultante" $(104,105,112)$ o en la "experiencia del enfermar" (62) o, más allá aún, en el modelo bio-psico-social (23, 104, 112, 125), etc. (tabla 7). Desde esta perspectiva -y no sólo desde la hermenéutica-, se entiende que la problemática del sentido o el significado se haya convertido en un punto crucial para todas las técnicas de psicoterapia no estrictamente empiristas (Mahoney, 1991:56). Y tanto a nivel teórico como a nivel epistemológico, temas que ya intenté contribuir a explorar desde 1976 y 1978 --incluso en un ámbito tan fundamental como el de la propia definición de la psicología como ciencia de la conducta (significante).

Además, cualquiera que sea nuestra postura teórica, es cierto que hay una coincidencia también en que "sentido" significa relación; que son las relaciones, internas y externas, las que confieren el significado de las conductas y representaciones mentales. Y que lo hacen a través de las emociones vividas en las relaciones (presentes o pasadas). En ese sentido, un elemento teórico y epistemológico básico ha de ser el reconocimiento incluso epistemológico del valor de la emoción: es la emoción la que confiere el significado de las vivencias humanas. Con lo que está resultando cada vez más claro que el compromiso científico en el campo de las ciencias humanas, como diría Mahoney (56), incluye un esfuerzo en pos del significado, lo cual ya había sido percibido por los autores psicoanalíticos, existenciales y humanísticos de nuestras disciplinas.

A mi entender, el psicoanálisis --y otras formas de psicoterapia-- podrían haber supuesto una aportación importante en este terreno epistemológico o, más ampliamente, en este terreno en el que gnoseología y epistemología pueden coincidir. Y podría haber sido así tanto a partir de sus nociones más elementales 
(inconsciente dinámico, procesos primario y secundario, mecanismos de defensa, compulsión de repetición, etc.) como a partir de conocimientos o conceptos más modernos, tales como el yo temprano, la fantasía inconsciente, la identificación proyectiva, las posiciones, una teoría suficientemente desarrollado de los afectos o emociones (91-92), la visión psicoanalítica de los procesos de simbolización, los "puntos de vista metapsicológicos kleinianos” (93). En el mismo sentido, las perspectivas de la psicología de los constructos personales y otras formas de constructivismo en psicoterapia, numerosas aproximaciones cognitivo-conductuales, las perspectivas sistémicas, etc. contienen, al menos en germen, numerosos elementos de esta epistemología derivada.

En último extremo, a nivel clínico, estas reflexiones suponen una cierta oposición con respecto a determinadas corrientes psiquiátricas de corte empirista que han venido insistiendo en la importancia de la realidad externa --biológica o social-- en la determinación de la psico(pato)logía y de las pautas relacionales. Desde mi perspectiva, por el contrario, acostumbro a mantener, junto con el conductismo radical, que el objeto de la psicología es la conducta en tanto que observable. Sus objetos concretos de estudio, los diversos actos de conducta. En igual sentido, se podrá definir la psico(pato)logía, disciplina de base de la psiquiatría, como la disciplina psicológica dedicada al estudio científico de la conducta o el comportamiento trastornado $o$ anómalo. De ahí nuestra costumbre coyuntural, tomada de Castilla $(13,14)$ de escribir siempre psico(pato)logía, para hacer hincapié en la religación fundamental para la psicopatología: su relación con la psicología.

Desde este punto de vista, en el estudio de la conducta significante (psico(pato)logía) y en su tratamiento, caso de que sea necesario (psiquiatría, psicoterapia), cabrían perfectamente hoy en día:

a) Orientaciones basadas en el estudio de la conducta "física", energética, directamente visible y mensurable con muy pocos instrumentos teóricos previos: tal sería el caso de la aproximación propia del neoconductismo, de la "Behaviour Therapy" $y$, desde un punto de vista estrictamente biológico, de la neurofisiología, la psiquiatría biológica, etc.

b) Orientaciones basadas en el componente "informacional" de la conducta significante. Uno de las vertientes de esta orientación, casi únicamente descriptiva, sería la psicopatología clásica. Otra, el conjunto de psicologías ( p s iquiatrías ) "di námicas ", "sistémicas", basadas en la "teoría de la comunicación" y el "cognitivismo emocional". Naturalmente, hemos de aceptar que este tipo de aproximaciones pueden teñirse más fácilmente hoy día de subjetivismo, especulación e ideología, tanto por la reciente inauguración de muchas de ellas, como por el incipiente estado en el que se encuentran sus instrumentos teóricos y conceptuales, por la falta de claros modelos epistemológicos de referencia, por su propio tema y modo de aproximación al mismo, y por otros muchos motivos. Pero también hemos de aceptar hoy su utilidad heurística y como programas de investigación o de trabajo. 
7. Una reactualización de mis tesis sobre la epistemología de la Psico(pato)logía y la Psiquiatría.

Para terminar, se me ha ocurrido que podría hacerlo como un replanteamiento de las posiciones mantenidas en mi trabajo de epistemología de 1978, que me he negado a reeditar hasta hoy. Y creo que, para facilitar la crítica y la discusión sobre estos temas, lo mejor que puedo hacer es presentar mis ideas en forma de tesis. Esquemáticamente serían hoy las siguientes:

1. La Psicología ha de entenderse como una ciencia canónica, nomotética. La psicopatología ha de entenderse como una rama o apartado de esa ciencia nomotética, canónica. Necesitan, por tanto, estar fundamentadas en el uso de los métodos científicos y, entre ellos, del método experimental --el método de verificación de hipótesis de más alta jerarquía epistemológica.

2. Como tales ciencias o ramas científicas, sus enunciados serán de dos tipos: $L o$ (observacionales) y L t (teóricos). No es concebible una ciencia o una tecnología basadas en el mero empirismo y en la negación de los enunciados teóricos (y metateóricos).

3. Esos dos deberían ser (y son) los tipos de enunciados fundamentales de la psicopatología aplicada, que en el campo médico suele confundirse con la Psiquiatría. También esta técnicatecnología debería estar basada en enunciados teóricos y observacionales reconocidos como tales y no negados de forma epistemológicamente vergonzante.

4. Ahora bien: cada vez va extendiéndose más una disociación de la psico(pato)logía consecutiva al reduccionismo progresivo de la psiquiatría: así, existirá una psicopatología directamente vinculada a la psicología (psicología clínica, de la salud, de la conducta normal y anormal, psicoanálisis....) y una psicopatología directamente vinculada con la psiquiatría biologista y, por lo tanto, como una parte de las neurociencias.

5. Psiquiatría y Psicopatología, en tanto que tecnologías o disciplinas científicas han de basarse en enunciados comunicables, verificables, apofánticos y no contradictorios con los de las ciencias y tecnologías coetáneas (aunque en esta tesis sufrirá importantes variaciones según qué campos de la investigación estemos considerando, según qué programas de investigación, según que momentos o enfoques de la investigación...)

6. Porque el conocimiento científico de lo individual en ciencias humanas y a escala humana no ha de diferenciarse de forma cualitativa del conocimiento científico de lo general: en el estudio de lo individual, con las limitaciones éticas y metodológicas propias, pueden y deben utilizarse los diversos métodos científicos. Tampoco en la ciencia y en las tecnologías del sujeto cabe una postura Bambi -metodológicamente soft -como enfrentada a una postura Godzilla- metodológicamente hard.

7. La Psiquiatría hoy es un conjunto técnico-tecnológico, interdisciplinario con predominio biológico, orientado al estudio y tratamiento de los trastornos mentales.

8. Su objeto parece que cada vez más va derivando hacia el estudio $e$ intervención en las conductas 
anómalas o trastornadas, con un predominio, dentro de la perspectiva biopsicosocial, de los enfoques y terapias biológicos. Su sinécdoque reductora dentro del término de neurociencias a menudo implica una aceptación informal del dominio de lo biológico o incluso del reduccionismo biologista, que está desbordando la neurología hacia las ciencias psicológicas o "del comportamiento".

9. Esa perspectiva de la Psiquiatría y la Psicopatología como disciplinas de las neurociencias puede detener los programas de investigación psicológicamente fundamentados de ambas disciplinas. En ese sentido, hoy parecería que casi la única vía de desarrollo científico de la Psiquiatría es el biológico (en total dependencia de la biología humana) y, por tanto, que puede perderse su campo específicamente interdisciplinario: entre la psico(pato)logía (rama de la psicología), la sociología y la antropología, la medicina (rama de la biología), etc. El imperialismo desmedido del modelo médico biologista (que no es el modelo médico ni "biomédico" sino una sola forma de aquél) puede frenar el desarrollo de la Psicopatología, la Psicología y, posiblemente, de la misma Psiquiatría.

10. Aunque todavía en psicología, psicopatología y psiquiatría científicas coexisten hoy diversos modelos heurísticos y hermenéuticos que han des ser considerados programas de investigación en el sentido de Lakatos y que siguen dando frutos en el desarrollo de las ciencias de base: biología, psicología, sociología. Un ejemplo paradigmático es el de los modernos estudios de la teoría de la vinculación o del apego (33).

11.Parece que, hoy por hoy, pueden detectarse al menos cuatro paradigmas o programas de investigación claramente establecidos: el biológico, el cognitivo-conductual, el psicoanalítico y los modelos informacionales, sistémicos y cibernéticos.

12. Sin embargo, en consonancia con las tesis 8 y 9 , hemos de recordar que ese imperialismo del modelo medico biologista, incluso en su versión neurocientífica, está deformando y reduciendo el programa epistemológico de nuestras disciplinas, con una potencia creciente según se avanza desde la Psicología hacia la Psicopatología y la Psiquiatría (tesis 8).

13. Al tiempo que es dudosa su efectividad $y$ eficiencia actuales, pues la propia medicina ha evolucionado hacia modelos biopsicosociales y cibernéticos de base, con perspectivas epistemológicas de causalidad estructural, con las perspectivas teóricas de factores de riesgo y de protección, contención o resiliencia, con las perspectivas teóricas de la epidemiología clínica...

14.Porque no hay que olvidar que el objeto básico de la Psicología, la psicopatología y la psiquiatría son las conductas (molares, del organismo total, del sujeto) y los significados de las conductas (mediatizados particularmente por las emociones y la relación).

15.Parece que la epistemología más útil para el desarrollo actual de las ciencias y tecnologías es una epistemología constructivista basada en una 
gnoseología y ontología realista matizada (realismo interno, realismo no representativo, etc). A menudo, no quedará más remedio que combinar ese realismo (matizado) y monismo ontológicos con un cierto paralelismo epistémico o heurístico.

16.Aunque en la Psiquiatría actual es mucho may visible que en otras muchas técnicas y tecnologías el peso de dos errores (o frenos) epistemológicos fundamentales: el reduccionismo (biologista) y el empirismo gnoseológico y epistemológico.

17.Lo cual impide o dificulta un replanteamiento de nuestras investigaciones, teorías y prácticas: un replanteamiento que, a mi entender, debería venir marcado por las perspectivas de la importancia de la relación, la emoción y la solidaridad interhumana (o su ruptura) para la psiquiatría, la psicología clínica y para nuestras técnicas terapéuticas. Si tenemos en cuenta las aportaciones kuhnianas, creo que hoy habríamos de insistir, incluso desde el punto de vista teórico y epistemológico, en ese replanteamiento necesario y urgente de nuestras disciplinas: un replanteamiento basado en elementos ideológicos que ya apuntan dentro de paradigmas alternativos y que llevarían a revitalizar el valor técnico, teórico y epistemológico de la relación, lo emocional y la solidaridad $\mathrm{y}$, consecuentemente, de una aproximación constructivista a la relación profesional, a la práctica clínica y a la aproximación clínica.

18.En resumen, en todos los ámbitos de las disciplinas de la salud mental, y en especial en la psiquiatría, encontraremos influencias de los tres problemas metateóricos en los cuales he centrado esta comunicación: el reduccionismo biologista, el empirismo y la invasión ideológica basada en la insolidaridad, el sobrevivencialismo y el librecambismo ${ }^{6}$.

Permítanme terminar hoy de una forma que resume mi punto de vista epistemológico para nuestra joven y hoy a un tiempo exuberante y depauperada disciplina psiquiátrica. Exuberante en cuanto a avances técnicos y penetración mediática. Depauperada en cuanto a amplitud de perspectivas, modelos teóricos y pluralidad. Porque creo que, hoy por hoy, no avanzamos tan deprisa como muchos dicen y como a menudo nos creemos. Lo que no significa que no avancemos o que no debamos probar vías alternativas, a veces "política o epistemológicamente incorrectas”, para avanzar. Personalmente, creo que es útil en nuestro ámbito proseguir con la actitud que ejemplificó a menudo Sigmund Freud cuando se autocriticaba (1920: 37). Él mismo intentó resumirla en varias ocasiones parafraseando un verso que creía de Friedrich Rückert, pero que, a su vez, éste había parafraseado al traductor hispano-hebraico Yehuda ben Salomó al-Harizi, el cual había tomado prestado el tema al poeta árabe, nacido en Basora, Abu-Hariri:

"Si no se puede avanzar volando, bueno es progresar cojeando, pues está escrito que no es pecado cojear". ${ }^{7}$ 
Tabla 1

\section{COMPONENTES DE LA CALIDAD DE UNA TERAPIA CUALQUIERA}

\begin{tabular}{|c|c|}
\hline 1. Accesibilidad & $\begin{array}{l}=\text { Facilidad con la cual los consultantes } \\
\text { pueden obtener atención cuando la necesitan. }\end{array}$ \\
\hline 3. Continuidad & $\begin{array}{l}\text { = Forma de provisión de un cuidado o terapia, } \\
\text { según el estado del desarrollo tecnológico. } \\
=\text { La atención necesaria está coordinada entre } \\
\text { diferentes profesionales, dispositivos, organi } \\
\text { zaciones y a lo largo del tiempo. }\end{array}$ \\
\hline 4. Efectividad & $\begin{array}{l}=\text { Las técnicas o procedimientos se proporcionan por } \\
\text { término medio de forma adecuada, según el desarrollo } \\
\text { ecnológico medio ("eficacia real"). }\end{array}$ \\
\hline 5. Eficacia & $\begin{array}{l}\text { = Capacidad de una técnica para solucionar } \\
\text { los problemas para los cuales está indicada. }\end{array}$ \\
\hline 6. Eficiencia & $\begin{array}{l}\text { = Consumo de esfuerzos, economía, personal, } \\
\text { repercusiones indeseables, etc de una técnica. }\end{array}$ \\
\hline 7. Seguridad & $\begin{array}{l}=\text { Grado en el cual los procedimientos están } \\
\text { libres de azar o peligros potenciales. }\end{array}$ \\
\hline 8. Oportunidad & $\begin{array}{l}=\text { Grado en el cual la atención se proporciona } \\
\text { cuando se necesita. }\end{array}$ \\
\hline $\begin{array}{l}\text { 9. Satisfacción desde la perspectiva } \\
\text { del consultante y sus allegados. }\end{array}$ & $\begin{array}{l}\text { = Evaluación "objetiva" y mediante entrevista } \\
\text { de la satisfacción de los mismos. }\end{array}$ \\
\hline 10. Mejora en la calidad de vida. & $\begin{array}{l}\text { = Variación en la calidad de vida, evaluada } \\
\text { según los sistemas habituales, entre el "antes" } \\
\text { y el "después" (o "durante") de una terapia. }\end{array}$ \\
\hline 11. Balance autonomía / heteronomía. & $\begin{array}{l}\text { = Grado de incorporación de los pacientes y } \\
\text { sus familias en los procesos de decisión de la } \\
\text { técnica y en los procesos y procedimientos } \\
\text { exploratorios y terapéuticos. }\end{array}$ \\
\hline
\end{tabular}


DEBATES

Tabla 2

\section{EL REDUCCIONISMO}

Definición:

* Extensión-generalización abusiva de EXPLICACIONES Y MODELOS DE UN CAMPO CIENTÍFICO O TECNOLÓGICO A OTRO

* con FUNDAMENTOS ÚLTIMOS extracientíficos: ideológicos, económicos...

* con efectos tanto en la investigación científica como en la tecnología.

Sin embargo,

* La posibilidad de reducir o intercomunicar modelos y teorías puede suponer una ventaja epistemológica: favorece la unificación de conocimientos.

* El problema no es la intercomunicabilidad de teorías y modelos, sino la extrapolación de su NECESIDAD CONTÍNUA Y SOBREVALORADA

* Y la transmisión (a menudo subliminal) de que LA REDUCCIÓN A UNA DE ESAS CIENCIAS ES REQUISITO INDISPENSABLE

* para la demarcación como CIENCIA

* y/o para el PROGRESO

Diferenciaciones y delimitaciones:

* Hay que diferenciar la crítica del reduccionismo epistemológico de la crítica a la ciencia que sirve de base a la reducción.

Recordando, por tanto,

* El fundamento biopsicosocial de las disciplinas de la SMC.

* La fundamentación fundamental de la Medicina en la Biología (y secundaria en las ciencias psicológicas y sociales).

$($ Medicina $=$ Tecnología + técnica + artesanado + "arte clínico")

* Y que el REDUCCIONISMO es una DEFORMACIÓN EPISTEMOLÓGICA CON FUNDAMENTOS Y EFECTOS IDEOLÓGICOS 
Tabla 3

\section{DIFERENCIAS FORMALES Y EPISTEMOLOGICAS ENTRE CIENCIA Y TECNOLOGÍA \\ (modificada de Quintanilla, 1978, 1981 y Tizón 1995)}

\begin{tabular}{|c|c|c|}
\hline \multicolumn{2}{|c|}{ EXPLICACIÓN CIENTÍFICA } & APLICACIÓN TECNOLÓGICA \\
\hline Explanans & 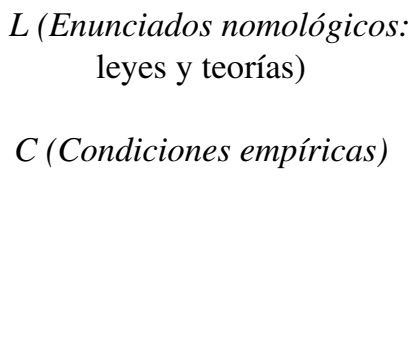 & $\begin{array}{c}P \text { Enunciado prescriptivo: } \\
\text { "Hay que conseguir el resultado } \mathrm{P} \text { " } \\
\text { L Enunciado nomológico: } \\
\text { por ejemplo, "Q --> P". } \\
\text { Lp Enunciado nomopragmático: } \\
\text { "Si se produce Q, se obtiene P". }\end{array}$ \\
\hline Explanandum & $\begin{array}{c}\text { A } \\
\text { (Acontecimiento a explicar) }\end{array}$ & $\begin{array}{c}R \text { Regla de actuación: } \\
\text { "Si quieres } \mathrm{P} \text {, haz Q". } \\
\text { Qp ("Haz Q") }\end{array}$ \\
\hline
\end{tabular}

Tabla 4

\section{DIFERENCIAS FORMALES Y EPISTEMOLOGICAS ENTRE CIENCIA Y TECNOLOGÍA (II) \\ (modificada de Quintanilla, 1978, 1981 y Tizón 1995)}

\begin{tabular}{|l|c|c|c|}
\hline & & $\begin{array}{c}\text { INVESTIGACIÓN } \\
\text { "PURA" }\end{array}$ & $\begin{array}{c}\text { INVESTIGACIÓN } \\
\text { TECNOLÓGICA }\end{array}$ \\
\hline Punto de partida & $\mathrm{C}$ & $\begin{array}{c}\text { Acontecimiento a explicar } \\
\text { Condiciones en las } \\
\text { que se produce } \mathrm{A} .\end{array}$ & $\begin{array}{c}\text { Resultado a producir } \\
\text { Condiciones en las que } \\
\text { conviene producir A }\end{array}$ \\
\hline Objetivo & $\mathrm{L}$ & $\begin{array}{c}\text { Ley o teoría que explique } \\
\text { la dependencia de A } \\
\text { respecto de C }\end{array}$ & $\begin{array}{c}\text { LEY que permita elaborar } \\
\text { una REGLA para } \\
\text { producir A a partir de C }\end{array}$ \\
\hline
\end{tabular}


DEBATES

Tabla 5

ALGUNOS DATOS SIGNIFICATIVOS SOBRE LA PARTICIPACIÓN DE LOS PSIQUIATRAS EN LAS TROPELÍAS DE LA ERA NAZI

\begin{tabular}{|c|c|c|c|}
\hline Año & Abuso & Cuantificación & $\begin{array}{l}\text { Observa } \\
\text { ciones }\end{array}$ \\
\hline 1934-39 & $\begin{array}{l}\text { Esterilización de "enfermos mentales" reales } \\
\text { o supuestos }\end{array}$ & $\begin{array}{l}350.000 \\
(0 ’ 5 \% \text { de la } \\
\text { población })\end{array}$ & $\begin{array}{l}\text { Con sólo } \\
\text { Alemania }\end{array}$ \\
\hline $1938-42$ & $\begin{array}{l}\text { Un equipo dirigido por psiquiatras selecciona } \\
\text { a gitanos alemanes para su esterilización y pos- } \\
\text { terior internamiento en campos de concentración } \\
\text { De ellos, son asesinados en Auschwitz }\end{array}$ & 20.000 & \\
\hline $1940-41$ & $\begin{array}{l}\text { Evaluados como incurables por un equipo de } \\
\text { psiquiatras asesina con gas a enfermos mentales } \\
\text { alemanes a cargo de equipos de exterminio } \\
\text { dirigidos por psiquiatras ( } 10 \text { de ellos, profe- } \\
\text { sores universitarios: de Crinis, Heyde, Mauz, } \\
\text { Nische, Panse, Pohlisch, Reisch, } \\
\text { Carl Schneider, Villinger, Zucker) }\end{array}$ & 70.000 & $\begin{array}{l}\text { "Los } \\
\text { escritores } \\
\text { de } X "\end{array}$ \\
\hline $1941-45$ & $\begin{array}{l}\text { Los pacientes mentales que sobrevivieron a esa } \\
\text { suerte de genocidio mueren en las instituciones } \\
\text { psiquiátricas por hambre, infecciones o tratami- } \\
\text { entos inadecuados o aventurados }\end{array}$ & $\begin{array}{c}80 \% \text { de los } \\
\text { sobrevivientes }\end{array}$ & $\begin{array}{l}\text { "Lastre } \\
\text { Humano", } \\
\text { "Conchas } \\
\text { vacías", } \\
\text { Vidas que } \\
\text { no merecen } \\
\text { vivirse" }\end{array}$ \\
\hline 1940-44 & $\begin{array}{l}\text { Florecimiento de la investigación anatomopato- } \\
\text { lógica a expensas del asesinato de enfermos } \\
\text { concretos (participación de figuras relevantes } \\
\text { como Carl Schneider, Heinze y Hallervorden) }\end{array}$ & & \\
\hline $1940-41$ & $\begin{array}{l}\text { Los mismos equipos asesinan con gas a los } \\
\text { pacientes mentales judíos y no alemanes } \\
\text { (Polonia, URSS...) }\end{array}$ & $\begin{array}{l}\text { Prácticamente, } \\
\text { la totalidad de } \\
\text { los pacientes de } \\
\text { los territorios } \\
\text { ocupados. }\end{array}$ & $\begin{array}{l}40.000 \\
\text { mueren de } \\
\text { hambre } \\
\text { bajo Vichy }\end{array}$ \\
\hline 1941 & $\begin{array}{l}\text { Los psiquiatras "escritores de X" intentan que se } \\
\text { apruebe una ley para protegerse con una base: } \\
\text { "Puede acabarse con la vida de un enfermo que } \\
\text { necesitaría cuidados de por vida, mediante } \\
\text { medidas médicas y sin su conocimiento" }\end{array}$ & & \\
\hline
\end{tabular}




\begin{tabular}{|c|c|c|}
\hline 1941 & $\begin{array}{l}\text { El primer comandante de Treblinka, dedicado } \\
\text { al exterminio de judíos, fue un psiquiatra: Eberl. }\end{array}$ & \\
\hline $1941-45$ & $\begin{array}{l}\text { Numerosos asesinos de las Einsatztruppen } \\
\text { sufren crisis nerviosas: los psiquiatras les } \\
\text { trataron para que volvieran a su "trabajo": } \\
\text { ¿delirio esquizofrénico humanitario? }\end{array}$ & $\begin{array}{l}\text { Hay casos } \\
\text { descritos }\end{array}$ \\
\hline 1946 & $\begin{array}{l}\text { Gran parte de los psiquiatras implicados en } \\
\text { asesinatos de pacientes son puestos en } \\
\text { libertad y continúan ejerciendo la profesión }\end{array}$ & \\
\hline Siempre & $\begin{array}{l}\text { La ideología y los términos "científicos" } \\
\text { crean realidad }\end{array}$ & \\
\hline
\end{tabular}

Müller-Hill B. La psiquiatría en la era nazi. En S. Bloch y P. Chodoff (eds). Psychiatric Ethics. Oxfcord: Oxford Medical Pub. 1991 (traducción en www. txoriherri.com visitada en marzo del 2002)

Tabla 6

Disposición de los médicos-USA a participar en Ejecuciones de Pena de Muerte (encuesta sobre 1.000 médicos en activo seleccionados aleatoriamente, antes del 11 de septiembre del 2001)

\begin{tabular}{|l|c|}
\hline \multicolumn{1}{|c|}{ VARIABLES en las respuestas } & $\begin{array}{c}\text { Porcentaje y } \\
\text { Otros Estadísticos }\end{array}$ \\
\hline Dispuesto a colaborar en alguno de los pasos médicos necesarios & $41 \%$ \\
En cinco o más pasos. & $25 \%$ \\
Dispuestos a aplicar la inyección letal. & $19 \%$ \\
Conocían que dicha participación está prohibida por la AMA & $3 \%$ \\
(iy por el juramento hipocrático!) & \\
Correlacionan con esa disposición a participar en acciones ilegales: & \\
Percepción de deuda con la sociedad & $\mathrm{p}<0.001$ \\
Apoyo a la pena de muerte & $\mathrm{p}<0.001$ \\
Apoyo al suicidio asistido & $\mathrm{p}=0.015$ \\
\hline
\end{tabular}

Farber NJ, Aboff BM, Weiner J, Davis EB, Gil E, Ubel PA. Physicians'Willingness To Participate in the Process of Lethal Injection for Capital Punishment. Annals Internal Med 2001; 135: 884-888. 
DEBATES

Tabla 7

COMPARACIÓN GENERAL DE DOS MODELOS MÉDICOS GLOBALES

\begin{tabular}{|c|c|c|}
\hline NIVEL & $\begin{array}{l}\text { MODELO MÉDICO } \\
\text { TRADICIONAL, } \\
\text { MÓDICO-BIOLÓGICO }\end{array}$ & $\begin{array}{l}\text { MODELO DE LA ATENCIÓN } \\
\text { SANITARIA CENTRADA } \\
\text { EN EL CONSULTANTE }\end{array}$ \\
\hline Teórico & Mecanicismo & $\begin{array}{l}\text { Causación: } \\
\text { múltiple } \\
\text { multiaxial } \\
\text { probabilística } \\
\text { con retroacciones causales }\end{array}$ \\
\hline Metateórico & $\begin{array}{l}\text { empirismo } \\
\text { dualismo } \\
\text {. biologismo }\end{array}$ & $\begin{array}{l}\text { Constructivismo } \\
\text { Monismo (o paralelismo epistémico) } \\
\text { Perspectiva interdisciplinaria } \\
\text { con predominio biológico. }\end{array}$ \\
\hline Ideológico & $\begin{array}{l}\text {. Sanidad = } \\
\text { ¿negocio, } \\
\text { "servicio", } \\
\text { "sacerdocio"?... . } \\
\text { Individualismo }\end{array}$ & $\begin{array}{l}\text { Sanidad = Servicio Social } \\
\text {. Alguna forma de comunitarismo }\end{array}$ \\
\hline Práctico & $\begin{array}{l}\text { Entrevista dirigida } \\
\text {. Maquinización }\end{array}$ & $\begin{array}{l}\text { Tecnologías biológicas y sociales... } \\
\text {. a propósito de la comunicación } \\
\text { digital y analógica. }\end{array}$ \\
\hline
\end{tabular}

(Tomada de Tizón, 1995).

\footnotetext{
${ }^{1}$ Texto de la ponencia presentada en las XVIII Jornadas de la Asociación Española de Neuropsiquiatría: "Siglo XXI: Crisis de los paradigmas. ¿De la Psicología a las Neurociencias? (Huelva 4-6 de abril de 2002).

${ }^{2}$ Primera edición inglesa: 1962; primera traducción al castellano: 1971

${ }^{3}$ Como la democracia, cuyas potencialidades actuales tienen más que ver con el respeto y la integración de las minorías que con la entrega del poder total a las mayorías, mayorías hoy casi siempre más que discutibles, justificables y matizables.

${ }^{4}$ Más sinécdoque y metáfora que realidad puesto que, como recordé más arriba, el planteamiento "neurocientífico", desde su propio término intenta la inclusión-dominación de las aportaciones de lo psicológico y lo social por parte de lo neurológico: porque en esos programas de investigación en pocas ocasiones hay una real interdisciplinariedad y porque la declaración de monismo que postula ese planteamiento no suele ser sino una negación reduccionista (al biologismo) del paralelismo heurístico y hermenéutico reales, muy difíciles de evitar con el grado actual de nuestros conocimientos
} 


\footnotetext{
${ }^{5}$ Dicho sea de paso, pero con toda la gravedad que implica, parece una impresionante muestra de la guerra comercial a la que me refiero y del uso del efecto Utah lo que la propia empresa fabricante, en la monografía de lanzamiento, atestigua: En su apartado de "seguridad y tolerabilidad" se afirma que "un total de 1.436 pacientes han sido tratados con el producto en estudios a largo plazo; de ellos, 400 han seguido tratamiento durante más de un año". Llama la atención que baste tratar a 1.436 pacientes para lanzar un producto que puede recibir entre el 0'2 y el 0'5\% de la población y que se considere un "estudio de seguridad y tolerabilidad a largo plazo" el que como media, iino dura ni un año!!.

${ }^{6}$ Prefiero hablar de librecambismo en vez de liberalismo para hacer hincapié por un lado, en una cierta exactitud histórica y económica: lo que se propala ideológicamente hoy en gran parte del Imperio y aledaños es un modelo económico librecambista, no un modelo social y filosófico liberal (el liberalismo social y filosófico). Este, además, posee muy diversas versiones: una de las menos conocidas en Europa es la de los liberales norteamericanos, a muchos de los cuales aquí los consideraríamos "socialistas o anarquistas de izquierdas". En todo caso, no conviene olvidar que las prácticas librecambistas en nuestros estados están coincidiendo con prácticas sociales y políticas antiliberales (en casi todos los sentidos del término).

${ }^{7}$ Traducción de JL López Ballesteros para Biblioteca Nueva: Madrid 1974. JL Etcheverri hace para Amorrortu otra traducción: "Lo que no puede tomarse volando / hay que alcanzarlo cojeando/... La Escritura dice: cojear no es pecado" (Buenos Aires: Amorrortu, 1979).
}

\section{BIBLIOGRAFÍA}

1. Anguera T. Anguera, M.T. (Ed.). Metodología observacional en la investigación psicológica. Barcelona: PPU 1991.

2. Barraquer Ll. Las pesadillas y la "actuación conductual” durante el sueño REM. Neurología 2001; 16: 214-220.

3. Beck, A.T., \& Emery, G. Anxiety and phobias: A cognitive approach. New York: Basic Books. 1985

4. Beck, A.T., \& Freeman, A. Cognitive therapy of personality disorders. New York: Guilford Press 1990.

5. Bell D (ed.). Psychoanalysis and Culture: A kleininan Perspective. London: Duckworth 1999.

6. Bernal,J.D. Historia social de la ciencia. Barcelona: Península 1964.

7. Bofill P., Tizón JL. Qué es el psicoanálisis: Orígenes, temas e instituciones actuales. Barcelona: Herder, 1994. (368 págs).

8. Bunge, M.. La investigación científica. Barcelona: Ariel 1969.

9. Bunge, M. Tecnología y filosofía. México: Universidad Autónoma de León. 1976.

10. Bunge, M.. Epistemología. Barcelona: Ariel. 1980.

11. Bunge, M. (1985). Philosophy of science and technology. In Treatise on basic Philosophy, Vol VII. Dordrecht: Reidel.

12. Casino G. Los fármacos causan el $12 \%$ de los ingresos. El País, 26 de febrero del 2002: 32.

13. Castilla, C. Introducción a la psiquiatría (I): Problemas generales. Psicopatología. Madrid: Alianza Universidad 1978.

14. Castilla, C. Prólogo. Inidentidad epistemológica de la psico(pato)logía. En J.L. Tizón, Introducción a la epistemología de la psicopatología y la psiquiatría. Barcelona: Ariel. 1978.

15. Castilla C. El delirio, un error necesario. Oviedo: Nobel 1998.

16. Clavero, J. La investigación bajo sospecha. Quadern CAPS, 1991, 15: 55-65.

17. Cruz-Hernández M. Filosofía Árabe. Madrid:Alianza 1963.

18. Damasio AR. Descarte's Error. New York: Putnam 1994..

19. De la Mata I, Ortiz A. Sesgos y dificultades en la investigación de los nuevos antipsicóticos. Rev. Asoc. Esp. Neuropsiq. 2001;21 (79): 57-74. 
DEBATES

20.Eisenberg L. The Social Construction of Human Brain. Am J Psychiatry 1995, 152,11: $1563-1575$.

21.Ekman P. Facil expression and emotion. Amer. Psychologist 1993; 48: 384-392.

22. Ekman P. Who can catch a liar? Amer Psychologist 1991;46: 913-920.

23.Engel, G.L. The need for a new medical model. Science 1986;, 196,:129-135.

24.Epstein H. Vida y muerte a escala social. Revista de Occidente 1999; 215: 19-47.

25.Epstein RM. The patient-pshysician relationship. En MB Mengel y WL Molleman (eds.). Fundamentals of Clinical Practice: A textbook on the Patient, Doctor and Society. New York: Plenum Medical Books 1996 (pp. 105-132).

26.Epstein R, Hundert EM. Defining and Assessing Professional Competence. JAMA 202; 287: 226-233.

27.Farber NJ, Aboff BM, Weiner J, Davis EB, Gil E, Ubel PA. Physicians'Willingness To Participate in the Process of Lethal Injection for Capital Punishment. Annals Internal Med 2001; 135: 884-888.

28. Ferrater J. Diccionario de Grandes filósofos. Madrid: Alianza 1994.

29. Ferrater J. Diccionario de filosofía. Barcelona: Edhasa 1978.

30. Feyerabend P. Contra el método. Ensayo de una teoría anarquista del conocimiento. Barcelona: Ariel 1974.

31. Feyerabend P. Adiós a la razón. Madrid: Tecnos 1984.

32. Feyerabend P. Consuelos para el especialista. En I. Lakatos y A. Musgrave (eds.). La crítica y el desarrollo del conocimiento. Barcelona: Grijalbo 1975.

33. Fonagy P. Attachement Theory and Psychoanalysis.New York: Other Press 2001

34.Frank, J.D. Elementos terapéuticos compartidos por todas las psicologías. En M.J. Mahoney y A. Freeman (Eds.), Cognición y psicoterapia (pp. 73-102). Barcelona: Piados 1985.

35. Frank, J.D. Psicoterapia, retórica y hermenéutica: Implicaciones para la práctica y la investigación. Revista de Psicoterapia, 1990; 1, 26-38.

36. Freixas J, Tizón JL. Filosofía de la Ciència i Psicoanàlisi: Consideracions sobre un mal enteniment. Revista Catalana de Psicoanàlisi 1984, 1 (1): 172-193.

37. Freud, S. (1920). Más allá del principio del placer. Obras Completas de S. Freud, tomo 8. Madrid: Biblioteca Nueva 1974. También en Sigmund Freud, Obras Completas, tomo 18. (pp. 1-63). Buenos Aires: Amorrortu 1979.

38. García de la Villa JM. ¿Existe una ciencia independiente?. Siso/Saude 2001; 35: 92-95.

39. Goldberg DP, Huxley P. Common Mental Desorders: A biosocial model. London: Tavistock/Routledge 1992.

40. Hinshelwood RD: Commentary: Symptoms or relationships. BMJ 2002; 324: 292.

41. Holmes J, Neighbour R, Tarrier N, Hinselwood RD, Bolsover N. All you need is cognitive behaviour therapy? BMJ 2002; 324:288-294.

42. Hospers J. Introducción al análisis filosófico. Madrid: Alianza 1976.

43. Isohanni MK, Isohanni I, Jones PB, Croudace TJ, Marjo-Riita J, Jokelainen J, Riala K. Social sequels of mental disorders in the 1966 North Finland Birth Control. American Psychiatric Association, 2001 Anual meeting Report Sessions Book. Session 12: Predictors in Schizophrenia. Washington: APA 2001.

44. Joint Commission on Accreditation of Healthcare Organizations. Primer on Indicator Development and Application: Measuring Quality in Health Care. Illinois: Joint Commission 1990 
45. Jones PB, Cruodace TJ, Moilanen K, Marjo-Riita J, Jokelainen J, Rantakalio P, Isohanni MK. Perinatal brain damages and slower development interact as risks for psychosis. American Psychiatric Association, 2001 Anual meeting Report Sessions Book. Session 12: Predictors in Schizophrenia. Washington: APA 2001.

46. Kandel ER. A new intellectual framework for Psychiatry. Am J Psychiatry 1998; 155: 265-277.

47. Kandel ER. Biology and the future of psychoanalysis: A new intellectual framework for Psychiatry revisited. Am J Psychiatry 1999; 156: 505-524.

48. Kendell RE. The next 25 years. Br.J Psychiatry 2000;176: 6-9.

49. Kendler KS y Robinette CD: Schizophrenia in the National Academy of Sciencies-National Research Council Twin Registry: a 16-year update. Am J. Psychiat 1983,140: 1551-1563.

50. Koehl M, Lemaire V, Vellée M, Abrous N, Piazza PV, Mayo W, Maccari S, Le Moal M. Acontecimientos vitales en el período perinatal: Efectos a largo plazo sobre el neurodesarrollo y la conducta. En Palomo T, Beninger RJ, Jiménez-Arriero MA, Borrell J, Archer T. Trastornos cognitivos. Madrid: Fundación Cerebro y Mente 2001. (pp 51-75).

51.Kuhn TS. Consideración en torno a mis críticos. En I. Lakatos y A. Musgrave (eds.). La crítica y el desarrollo del conocimiento. Barcelona: Grijalbo 1975.

52. Kuhn TS. Lógica del descubrimiento o psicología de al investigación. En I. Lakatos y A. Musgrave (eds.). La crítica y el desarrollo del conocimiento. Barcelona: Grijalbo 1975.

53.Lakatos I (ed). La crítica y el desarrollo del conocimiento. Barcelona: Grijalbo 1975.

54. Lakatos I. La historia de la ciencia y sus reconstrucciones racionales. En I. Lakatos y A. Musgrave (eds.). La crítica y el desarrollo del conocimiento. Barcelona: Grijalbo 1975.

55.Le Doux J. The Emotional Brain. New York: Simon \& Schuster 1996.

56. Mahoney, M.J. Human change processes. New York: Basic Books 1991.

57. Manheim, K. Ideología y utopía. Introducción a la sociología del conocimiento. Madrid: Aguilar 1966.

58. Marmot MG, Davey G, Stansfield S. Health inequalities among British civil servants: The Whitehall II Study. Lancet 1991; 337: 1387-1393.

59. Marmot MG, Shipley MJ, Rose G. Inequalities in death-specific explanations of a general pattern? Lancet 1984;1: 1003-1006.

60. Marshall M, Gray A, Lockwood A, Green R. Case managemente for people with severe mental disorders. En Adams CE, Duggan L, Wahlbeck K, White P (eds). Schizophrenia Module of the Cochrane Database of Systematic Reviews. Oxford: Update Software 1998.

61. Méndez R. Demasiada dosis contra el colesterol. La retirada del fármaco Lipobay conmociona un mercado que mueve al año 2'7 billones de pesetas. El País 2001: domingo 12 de agosto, 19.

62. Morse JM \& Jonhson JL (eds). The Illness experience: Dimensions of suffering. New York: Sage 1991.

63. Mosterín J. Conceptos y teorías en la ciencia. Madrid: Alianza 1984.

64. Muguerza J. Desde la perplejidad. Madrid: FCE 1990.

65. Muguerza J. Introducción. En I. Lakatos y A. Musgrave (eds.). La crítica y el desarrollo del conocimiento. Barcelona: Grijalbo 1975.

66. Müller-Hill B. La psiquiatría en la Era Nazi. En S. Bloch y P. Chodoff (eds.). Psychiatric Ethics. Oxford: Oxford Medical Pub. 1991. (traducción castellana: txoriherrri.medical records, www.txoriherri.com, visitada en febrero del 2002).

67. Musgrave AM. Los segundos pensamientos de Kuhn. Valencia: Cuadernos teorema 1978.

68. Olivé L. Racionalidad epistémica. Enciclopedia Iberoamericana de Filosofía (vol 9). Madrid: Trotta 1995. 
69.Pally R. Memory: brain systems that link past, present and future. Int J Psychoanalysis 1997; 78: 1223-1234.

70.Pally R. Procesamiento emocional: La conexión mente-cuerpo. Libro Anual de Psicoanálisis 2000, 14: 191-205.

71.Piaget, J. (Dir.) Logique et connaissance scientifique. Dijon: Gallimard. 1969.

72.Piaget, J. La situación de las ciencias del hombre dentro del sistema de las ciencias. En J. Piaget, W.J.M. Mackenzie, y P.F. Lazarsfeld (Ed.), Tendencias de la investigación en las ciencias sociales. Madrid: Alianza. 1973.

73. Piaget, J. La naissance de l'intelligence chez l'enfant. Neuchaâtel: Delachaus et Niestlé. 1975.

74.Piaget, J. Sabiduría e ilusiones de la filosofía. Barcelona: Penninsula. 1977.

75. Pinker S. How the Mind Works. New York: WW Norton 1997.

76.Popper K. Conjectures and Refutations: The Growth of Scientici Knowledge. Londres: Rutledge and Keagan 1967.

77.Popper K. La ciencia normal y sus peligros. En I. Lakatos y A. Musgrave (eds.). La crítica y el desarrollo del conocimiento. Barcelona: Grijalbo 1975.

78. Quintanilla MA. A favor de la razón. Madrid: Taurus 1981.

79. Quintanilla MA. Tecnología: Un enfoque filosófico. Madrid: Fundesco 1989.

80. Quintanilla MA. Tecnología y Sociedad. Lima: Universidad Inca Garcilaso 1999.

81. Quintanilla MA. La tecnología como paradigma de acción racional. Revista de Occidente 2000;5

82. Quiroga P. Esquizofrenias y genética: Revisión. Santiago de Compostela: Asociación Galega de saúde Mentale, 1997.

83. Rubia K Smith A. Attention deficit-hyperactivity disorder: current findings and treatment. Current Opinion in Psychiatry 2001;14: 309-316.

84. Rubio G, Ponce G, Jiménez-Arriero MA, Palomo T. Deterioro cognitivo asociado al uso de psicofármacos y a drogas de abuso: posibilidades terapéuticas. En Palomo T, Beninger RJ, Jiménez-Arriero MA, Borrell J, Archer T. Trastornos cognitivos. Madrid: Fundación Cerebro y Mente 2001. (pp 207-221).

85. Rychlak, J.F.. Personalidad y psicoterapia. México: Trillas 1988

86. Sackett DL. Los pecados de la Experticidad y una Propuesta de redención. BMJ 2000, 320: 1283. (Traducción THM News).

87. Sánchez, A. (1976). La ideología de la neutralidad ideológica en las ciencias sociales. Zona Abierta, 1976;7, 67-83

88. Sandri R. (dir). L'observation du nourrisson selon Esther Bick. Lyon: Cesura, 1994.

89. Silberman S. The Geek Syndrome. Wired digital 2001;9-12: 1-6.

90. Spiro H, Mccrea MG, Peschel E, St.James D (eds). Empathy and the pracice of Medicine. New Have: Yale University Press 1993.

91. Stein R. Psychoanalytic Therories of Affect. London: Karnac 1999.

92. Stern DN, Sander LW, Nahum JP, Harrison AM, Lyons-Ruth K, Morgan AC, Bruschweiler-Stern N, Tronick EZ. Mecanismos no interpretativos en la terapia psicoanalítica: El "algo más" que la interpretación. Libro Anual de Psicoanálisis 2000;14: 207-225.

93. Tabak, E. Y Antar E. Mas allá de la metapsicología freudiana: los puntos de vista metapsicológicos de la escuela kleiniana. En Publicacioens del $33^{\circ}$. Congreso de la Asociación Psicoanalítica Internacional. Madrid: API. 1983.

94. Tizón JL. El discurso antipsiquiátrico. Fenomenología-Psiquiatría - Contracultura. Teorema, Revista de Lógica y Filosofía de la Ciencia 1972, 7: 5-34. 
95. Tizón JL. Una panorámica del discurso antipsiquiátrico R.D. Laing: De la Fenomenología a la Antipsiquiatría. Informaciones Psiquiátricas 1973, 55: 43-58.

96. Tizón JL. Los postulados psicosociológicos de J. Piaget. Informaciones Psiquiátricas 1975, $61(1-2): 3-16$.

97. Tizón JL. El psicoanálisis y la epistemología contemporánea. Teorema, Revista de Lógica y Filosofía de la Ciencia (Valencia), 1976, 6 (1): 161-187.

98. Tizón JL. Introducción a la epistemología de la psicopatología y la psiquiatría. Barcelona, Ariel, 1978

99. Tizón JL. Ideología y conductismo. Informaciones Psiquiátricas 1980, 78 (1): 65-67.

100. Tizón JL. Nueve tesis sobre la organización de unos dispositivos comunitarios de la Salud Mental. Revista Mensual/Monthly Review 1981, 4 (6-7): 39-55.

101. Tizón JL. Relaciones sociales y salud mental: Esquemas de la aportación psicodinámica a una aproximación no empirista. En MT Rossell MT, JL Tizón (comp.). Salud Mental y Trabajo Social. Barcelona, Laia 1983. (pp. 111-145).

102. Tizón JL (Coordinador) y De la Lama E, Díaz-Munguira JM, Salamero M (Compiladores). El biologismo: implicaciones teóricas, repercusiones en la asistencia sanitaria. (2 tomos publicados como extras de la revista Informaciones Psiquiátricas). Barcelona: Informaciones Psiquiátricas 1986.

103. Tizón, JL: Recuerdo (parcial) y repetición. Notas acerca del concepto de realidad a partir de la clínica psicoanalítica. Rev. de Psicoanálisis de Madrid, 1988, 8: 7-45.

104. Tizón JL: Componentes psicológicos de la práctica médica: Una perspectiva desde la Atención Primaria. Barcelona: DOYMA, 1988 (272 págs.) (4a ed.: Biblària, Barcelona, 1996).

105. Tizón, JL. "Sobre la fundamentación epistemológica de la Atención Sanitaria Centrada en el Consultante (en tanto que concreción de los nuevos modelos asistenciales)". En R. Ruiz, dir. Un nuevo modelo médico: bases teóricas y prácticas. (pp.35-67) Córdoba: Universidad Internacional Menéndez Pelayo - Knoll, 1993.

106. Tizón, JL.. Una reflexión acerca de los límites epistemológicos del psicoanálisis. En J. Font y J. Atxotegi (Comps), Filosofía de la Ciencia Hoy. Barcelona: Fundació Vidal i Barraquer, 1994 (pp. 73-96).

107. Tizón,JL, Freixas,J.: Filosofía de la Ciencia y Psicoanálisis: Demasiados malentendidos y malos entendimientos. Arbor, Revista del Consejo Superior de Investigaciones Científicas 1994. 585, 49-75

108. Tizón JL. Las psicoterapias psicoanalíticas breves y las terapias de flash. I. La evolución técnica de las psicoterapias breves. Informaciones psiquiátricas. 1994; 138 (4): 357-368.

109. Tizón, J.L. Las psicoterapias psicoanalíticas breves y las terapias de flash. II. Los procesos de sensibilización a lo psicológico, terapias de flash o psicoterapias ultrabreves. Informaciones psiquiátricas 1994; 138 (4): 369-392

110. Tizón, JL: Apuntes para una Psicología basada en la Relación. Barcelona: Biblària, 1995 ( $5^{\mathrm{a}}$ ed.).

111. Tizón JL. ¿Existen las “ciencias interpretativas”?: Una reflexión acerca de los límites epistemológicos del conocimiento psicoanalìtico. Anuario de Psicología (Barcelona) 1995, 67: 51-75.

112. Tizón JL. Los nuevos modelos asistenciales en Medicina: Una visión a partir de algunos de sus fundamentos psicológicos y epistemológicos. Revisiones en Salud Pública 1995,4: 57-83. 
113. Tizón JL. Apuntes para una Psicología basada en la relación. Barcelona: Biblària 1995

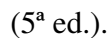

114. Tizón JL. Cognitivismo, psicoanálisis, psicobiología (I): )diferentes programas de investigación para un mismo objeto?. Rev. Psiquiatría Fac.Med. Barcelona (I) 1997,24,2: 82-92;

115. Tizón JL. Cognitivismo, psicoanálisis, psicobiología (II): Cognitivismo y psicoanálisis en las técnicas de psicoterapia. Rev. Psiquiatría Fac.Med. Barcelona 1997,24,4: 133-138.

116. Tizón JL. Cognitivismo, psicoanálisis, psicobiología (III): Una perspectiva hacia el futuro. Rev. Psiquiatría Fac.Med. Barcelona 1997, 24, 6: 163-176.

117. Tizón JL. La investigación empírica sobre las psicoterapias: Otra lente del "Hubble" defectuosa? En J. Vallejo (dir.). Update de Psiquiatría 1997. Barcelona: Masson, 1997 (pp. 67-99).

118. Tizón JL. Sobre el "Humanismo imposible" en la Medicina actual. Humana 1998,2,1: 5-8.

119. Tizón JL. Determinación y determinismo en psicopatología: I. Un problema filosófico? Archivos de Neurobiología 1999;62 (4): 277- 289.

120. Tizón JL. Determinación y determinismo en psicopatología: II. Una reflexión acerca de los diversos tipos de factores de riesgo. Archivos de Neurobiología 2000, 63, 1: 21-42.

121. Tizón JL. Psicopatología relacional de las Psicosis: Apuntes para la fundamentación del tratamiento psicológico de los trastornos psicóticos. Rev. de Psicosomática y Psicoterapia 2000, 20, 44: 25-78.

122. Tizón JL. Investigación y docencia en Salud Mental (I): Reflexiones para el clínico antes de la autoinmolación. Revista de la Asociación Española de Neuropsiquiatría 2001;21 (77):69-96..

123. Tizón JL. Investigación y docencia en Salud Mental (II): )Queda algún futuro para la "Asistencia Centrada en el Consultante" y el pensamiento clínico? Revista de la Asociación Española de Neuropsiquiatría 2001; 21,78: 73-101.

124. Tizón JL. ¿A qué se puede llamar atención a la salud mental y atención psiquiátrica "basadas en la evidencia"? Archivos de Psiquiatría 2002 (en prensa).

125. Tous, JA. El modelo biopsicosocial en la salud. Atención Primaria 1987; 4,2 :100-102.

126. Villagrán JM. ¿Necesitamos una nueva psicopatología descriptiva?. Archivos de Psiquiatría 2001; 64: 97-100.

*Psiquiatra de Atención Primaria, psicólogo, psicoanalista. Director de la Unidad de Salud Mental de Santa Martí (nord) del Institut Catalá de la Salut (Barcelona, España)

Correspondencia: Unidad de Salud Mental. Pza. de la Infancia, s/n - 08020-Barcelona

Recibido 19-05-02 